\title{
The design and optimisation of a monoblock divertor target for DEMO using thermal break interlayer
}

\author{
F. Domptail ${ }^{1}$, T.R. Barrett ${ }^{1}$, M. Fursdon ${ }^{1}$, A. Lukenskas ${ }^{1}$, J-H. You ${ }^{2}$ \\ 1 CCFE, Culham Science Centre, Abingdon, OX14 3DB, UK \\ 2 Max-Planck-Institut für Plasmaphysik, Boltzmannstr. 2, 85748 Garching, Germany
}

Email: fred.domptail@ukaea.uk

Keywords: DEMO, Divertor Target, Thermal Break, High Heat Flux, Design Optimisation

\section{Abstract}

A high performing DEMO divertor target mock-up design that uses the thermal break interlayer concept is presented. The design evolved from a previous design of which six mock-ups were designed, fabricated and subjected to high heat flux testing. The new design was generated using optimisation techniques; specifically, software was developed to automatically process the design of experiments data to enable visualisation of the design space. Despite the more challenging geometric constraints of this second phase, this design performs significantly better than that of the previous phase; the strain in the interlayer, which was the dominant damage mode in the phase 1 testing, is reduced by $28 \%$. Four mock-ups of the selected design were manufactured, all of which successfully passed a series of high heat flux testing, including $500 \mathrm{cycles}$ at $20 \mathrm{MW} / \mathrm{m}^{2}$. Design optimisation methods are not widely utilised in fusion engineering, their potential benefits, which are demonstrated here on a plasma facing component, could be applied to many other challenging designs.

\section{Introduction}

The work presented is part of the second phase of a EUROfusion WPDIV Divertor project that aims to produce a viable divertor target design for DEMO [1] [2]. The monoblock divertor designs that are being considered are largely based on the ITER vertical target [3]. They comprise a series of tungsten armour blocks with a $\mathrm{CuCrZr}$ cooling pipe joined to the tungsten via a soft copper interlayer, as shown in Figure 1. In addition to the "ITER-like" design, several alterative concepts are also being evaluated. During phase 1 , the thermal break concept was developed and 6 mock-ups of this design were manufactured and evaluated for their performance under high heat flux (HHF) testing using the IPP test facility GLADIS [4] [5] [6] [7].

The aim of this second development phase was to design an improved divertor target design using the knowledge gained during the design, fabrication and testing of the first phase [6]. The lifespan of monoblock divertor design is mostly limited by the stress caused by the thermal expansion mismatch between the tungsten armour and the CuCrZr cooling pipe [6] [8] (Figure 1). To improve the assembly performance, three design strategies have been used. They are the implementation of a thermal break interlayer, a compliant interlayer and heat flux redistribution; these strategies are detailed further in Section 2.4.

During the previous development phase, the additional feature of a split in the tungsten armour, between its plasma facing surface and the interlayer, was found to be of great benefit in relieving the stress in both the tungsten armour and the cooling pipe. In all the concepts presented here, one or in some cases two of these splits are included. For this second phase the geometric constraints and the heat flux requirements were updated. The updated geometry constraints for the mock-up are summarised in Figure 1. The dimensions that could be explored, to optimise the design, were the thickness and the shape of the interlayer and the thickness of the tungsten block, although $12 \mathrm{~mm}$ was the preferred dimension for the block thickness. All other dimensions were to be as shown in Figure 1. Note that this was more restrictive than the specification of phase 1 design where the diameter and thickness of the cooling pipe as well as the width of the block could be also be altered. The baseline heat load of $20 \mathrm{MW} / \mathrm{m}^{2}$ [9], was used for this design.

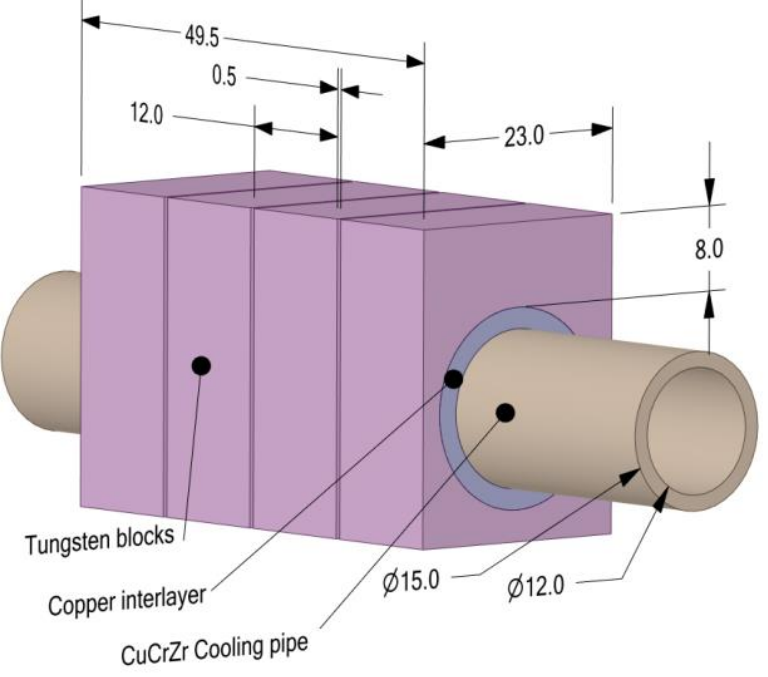

Figure 1: Sketch of geometric requirement for the second phase mockup design.

Based on the work conducted in another part of the WPDIV programme [10]\& [11], design criteria and objectives were defined to assess the performance of each design, they are detailed in Section 2.3.

Design search and optimisation procedures were used to seek the best performing design. These procedures rely on Design of Experiments ( $D o E$ ) that require many iterations of the Finite Element (FE) model. To allow the optimisations to be completed in a manageable time frame, a simplified model type was developed and validated. Geometrical dimensions were set as parameters for the DoE matrix, which was then populated with the results from FE analyses.

A program was developed in Python to automatically process the data from the DoE into surface responses and charts. This code greatly facilitated the design space exploration. The assessment and design optimisation strategy are described further in the next section. 


\section{Design assessment strategy}

\subsection{Software and codes}

The data presented was generated using the following system and software:

- $\quad$ Operating System: Microsoft Windows 7, Professional x64 Edition, Version 2009, SP1

- $\quad$ Finite Element Analysis (FEA): ANSYS Workbench Release 16.2

- Programming language: Python 3.5.2 - Distribution Anaconda 4.2.0 (64-bit) - includes numpy 1.12.1; scipy 0.19.0 and matplotlib 1.5.3.

\subsection{Modelling details}

This section describes the generic parameters used in all FE simulations presented.

\subsubsection{Geometry and boundaries}

Ideally analysis models would consider the complete mock-up assembly, as shown in Figure 1, but even when using symmetries, this is not practical for the large number of simulations needed. The high computational demand generated by the optimisation process would have been too time consuming. Instead a simplified and much smaller model was developed thus permitting each optimisation to be conducted in a manageable time frame.

Using two symmetry planes, the simplified model represents a quarter of a single monoblock (Figure 2). The continuous pipe constraint, at the middle of the gap between two tungsten blocks, is simulated by a planar boundary condition. This condition is applied by a non-separable sliding contact with a nearly undeformable and minimally-constrained additional block. This planar constraint allows for the free bending of the cooling pipe which is comparable to the high heat flux testing condition. One vertical displacement constraint is applied to both the mock-up and the nearly undeformable block to prevent rigid body motion. Note that the free-bending condition does not aim to replicate the in-service situation where the divertor target is rigidly pinned onto a cassette structure.

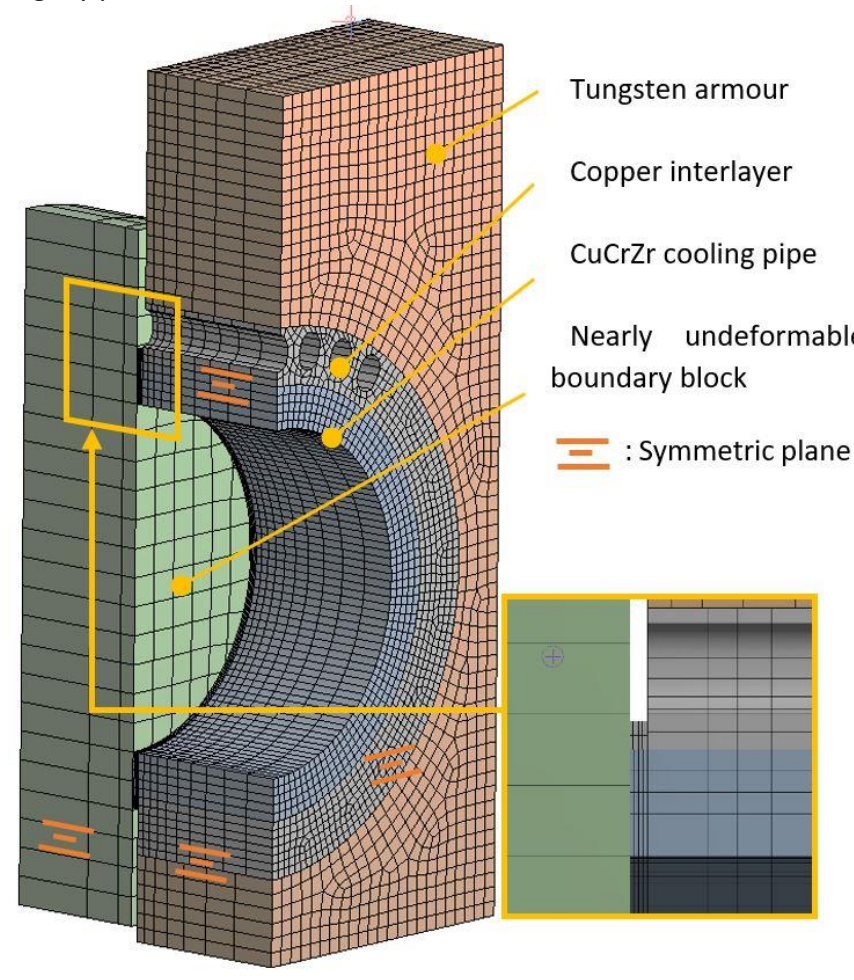

Figure 2: Typical FE mesh of the simplified model. of this validation can be found in Appendix B. It shows that the discrepancy between the full and the simplified model is within $10 \%$; thus rendering the simplified model as acceptable for the optimisation campaign.

\subsubsection{Mesh density}

A typical meshed geometry can be seen in Figure 2. To allow for fair comparison, the mesh parameters remain unchanged between models. This mesh yields results within $5 \%$ of a mesh with 4 times as many nodes, whilst solving around 20 times faster. All components are meshed with axial sweep methods, the parameters of which are summarised in Table 1.

\begin{tabular}{cc}
\hline Swept mesh parameters & $\begin{array}{c}\text { \# divisions / Bias / } \\
\text { Swept face element size } \\
{[\mathrm{mm}]}\end{array}$ \\
\hline Cooling pipe & $10 / 5 / 0.3$ \\
\hline Cooling pipe between armours & $4 / 0 / 0.3$ \\
\hline Interlayer & $10 / 5 / 0.3$ \\
\hline Interlayer between armours & $6 / 0 / 0.3$ \\
\hline Tungsten armour & $7 / 5 / 0.5$ \\
\hline Pipe end boundary block & $3 / 5 / 1.0$
\end{tabular}

Table 1: Mesh parameters

\subsubsection{Load and solution steps}

The loads and solution steps are as detailed in the guidelines for inelastic assessment [12]. The model loads can be defined as 4 thermal states: (1) Stress-free condition at $475^{\circ} \mathrm{C}$ when cooling down from the manufacturing / brazing process $\left(475^{\circ} \mathrm{C}\right.$ is the temperature of $\mathrm{CuCrZr}$ heat treatment and at which hardening occurs); this state enables accounting for the residual manufacturing stress; (2) room temperature at the end of the manufacturing process; (3) standby where no plasma heat load is applied and the component is in thermal equilibrium with the $130^{\circ} \mathrm{C}$ cooling water and (4) heat-load where the target is subject to the plasma heating of a nominal $20 \mathrm{MW} / \mathrm{m}^{2}$ to its top face (the actual values applied to the surface of the armour is $20.83 \mathrm{MW} / \mathrm{m}^{2}$ to account for the gap between monoblock which has no heat load input).

Note that the shaping of the armour, that is required to shadow leading edges and counteract potential misalignment due to assembly tolerances on the divertor assembly, will generate uneven heat flux loading [13]. This uneven heat loading is not considered in the present optimisation study; however, its effect can be significant, and it will need to be considered in the next stage of the design.

For the assessment of cyclic failure, 3 standby to heat-load cycles are applied.

A convective heat transfer boundary condition is applied to the bore of the pipe via an ANSYS command snippet. The convective heat transfer is determined according to the Sieder Tate correlation [14] [15] and was extracted using the Thermprop program [16] with water coolant temperature of $130^{\circ} \mathrm{C}$, pressure of $4 \mathrm{MPa}$ and velocity of $16 \mathrm{~m} / \mathrm{s}$, the test condition in GLADIS.

\subsubsection{Material properties}

Material properties are extracted from [17], as specified in the analysis guideline for plasma facing components [12]. Properties are taken as unirradiated. CuCrZr condition is assumed to be heat treatment B [17]. The CuCrZr pipe and the copper interlayer are modelled as elasto-plastic materials; the $\mathrm{CuCrZr}$ used the Chaboche kinematic hardening model whereas, to avoid for convergence issues, the copper used a bilinear kinematic hardening model. Data used is shown in Appendix A.

The validity of this simplified model was verified on a typical design, by comparing its simulation results with that of a full mock-up. Results 


\subsection{Optimisation criteria and objectives}

Criteria and objectives were derived from 3 sources: the divertor elastic design rule [10], a draft version of the guidelines for inelastic assessment of plasma facing components [12] and the work on the interpretation of deep cracking phenomenon in the tungsten armour [11]. Criteria and objectives are summarised in Table 2 below; rationales behind the criterion for each material are stated in the associated subsequent subsection.

\begin{tabular}{|c|c|c|}
\hline Parameters & Criterion ID & $\begin{array}{l}\text { Objective or } \\
\text { Constraint }\end{array}$ \\
\hline \multicolumn{3}{|l|}{ Tungsten armour: } \\
\hline Temperature Tungsten & $A$ & Const.: $<3222^{\circ} \mathrm{C}$ \\
\hline V.M. fluctuation, top face & B & Obj.: Minimise \\
\hline $\begin{array}{l}\text { Abs. tensile stress, top } \\
\text { face }\end{array}$ & C & Obj.: Minimise \\
\hline Tungsten P1 Standby & D & Const.: < 4.33E8 Pa \\
\hline Tungsten P1 Load & $\mathrm{E}$ & Const.: $<2.92 \mathrm{E} 8 \mathrm{~Pa}$ \\
\hline \multicolumn{3}{|l|}{ Cupper interlayer: } \\
\hline Temperature Interlayer & $\mathrm{F}$ & Const.: $<885^{\circ} \mathrm{C}$ \\
\hline Total Strain fluctuation & $\mathrm{H}$ & Obj.: Minimise \\
\hline \multicolumn{3}{|l|}{ CuCrZr Cooling pipe: } \\
\hline V.M. fluctuation & I & Const.: $<2.7 \mathrm{E} 8 \mathrm{~Pa}$ \\
\hline Total Heat Flux Pipe ID & J & Const.: $<4.63 \mathrm{E} 7 \mathrm{Wm}^{-2}$ \\
\hline Temperature pipe & K & Const.: $<450^{\circ} \mathrm{C}$ \\
\hline
\end{tabular}

Table 2: Summary of objective and constrain criteria for each material (for $20 \mathrm{MW} / \mathrm{m}^{2}$ nominal heat flux) - P1 refers to the first principal stress, $\mathrm{VM}$ to von Mises and fluctuations are from standby to load conditions.

\subsubsection{Tungsten armour}

\subsubsection{Temperature limit}

Tungsten allowable peak temperature [Criterion A] is limited by its melting point minus a $200^{\circ} \mathrm{C}$ temperature margin. Clearly, this limit far exceeds the re-crystallisation temperature of tungsten, but at such high levels of surface heat flux, it is accepted that some depth of recrystallised tungsten is unavoidable.

\subsubsection{Deep cracking}

Because of the imposed thick armour layer of this concept, temperatures above the recrystallisation level are expected on the top surface of the armour. Deep cracking was observed on monoblocks during high heat flux testing and is believed to be initiated by cyclic plastic strain in the recrystallised layer [11].

To guard against this phenomenon two criteria have been selected. The first is the von Mises fluctuation on the top face of the tungsten [Criterion B]; this is to account for crack formation by low cycle fatigue. The second criterion is the absolute tensile [Criterion $\mathrm{C}$ ] stress on the top face, which accounts for crack propagation or fast fracture. These criteria have been selected based on a study of deep cracking phenomenon of tungsten monoblock [11]. The applications are greatly simplified in the present study so that they are better suited for the optimisation study which requires many design iterations. Note that in the model used here, tungsten is modelled as a purely elastic material and the property changes associated with recrystallisation are not considered; consequently the first criterion [Criterion B] is selected as the von Mises fluctuation because it is directly correlated to the plastic strain that is expected of the recrystallised layer.

\subsubsection{Brittle fracture}

Brittle fracture is accounted for by limiting the absolute peak of the first principal stress anywhere in the tungsten to $1 / 3$ of its ultimate tensile strength (UTS). This criterion is assessed for both standby [Criterion D] and heat load conditions [Criterion E]. This limit is recommended by most pressure vessel codes for brittle material [6]. During standby conditions the assembly temperature is uniform at $130^{\circ} \mathrm{C}$ and during the heat flux load the peak tensile stress usually locates at the junction with the interlayer where the temperature is typically below $600^{\circ} \mathrm{C}$. At these temperatures, the UTS of tungsten is reported to be $1299 \mathrm{MPa}$ and $878 \mathrm{MPa}$, respectively [17]. Therefore, limits of $433 \mathrm{MPa}$ and $292 \mathrm{MPa}$ shall be used for the first principal stress for the standby and heat flux load, respectively.

\subsubsection{Copper interlayer \\ 2.3.2.1 Temperature limit}

The temperature of the interlayer is limited to its melting point minus a $200^{\circ} \mathrm{C}$ margin [Criterion F]. The preferred manufacture of the copper interlayer is to cast into the tungsten armour thus no additional temperature limit for a braze joint is required.

\subsubsection{Fatigue}

A second last criterion for the copper is to minimise its peak strain so that the fatigue life of the interlayer is maximised [Criterion $\mathrm{H}$ ].

\subsubsection{CuCrZr cooling pipe \\ 2.3.3.1 Temperature limit}

To guarantee negligible creep the temperature of the pipe should not exceed $300^{\circ} \mathrm{C}$ at $10 \mathrm{MW} / \mathrm{m}^{2}$ and $450^{\circ} \mathrm{C}$ at $20 \mathrm{MW} / \mathrm{m}^{2}$ [10] [17] (through thickness average). In the present study, only the temperature at $20 \mathrm{MW} / \mathrm{m}^{2}$ is verified [Criterion $\mathrm{K}$ ]; with the cooling water temperature set at $130^{\circ} \mathrm{C}$ this limit is more stringent than that at $10 \mathrm{MW} / \mathrm{m}^{2}$.

\subsubsection{Ratchetting}

The ratchetting ' $3 \mathrm{~S}_{\mathrm{m}}$ ' rule is extracted from [10]; it compares the fluctuating von Mises value between standby and heat-load condition to that of three times the design stress $S_{m}$. A limit of 270MPa [Criterion I] is used; this limit is based on an approximate peak mid-thickness temperature of $350^{\circ} \mathrm{C}$ where the design stress $S_{m}$ is around $90 \mathrm{MPa}$.

\subsubsection{Critical heat flux}

Peak heat flux into the coolant is limited to the critical heat flux value of $46.3 \mathrm{MW} / \mathrm{m}^{2}$ [Criterion J], which was calculated using [16] with the coolant parameters specified in section 2.2.3.

\subsection{Design strategy and automation of data processing}

Three design principles have been used to improve the performance, all motivated by reducing stress in the structural cooling pipe. These are: (1) Thermal break: where the tungsten temperature is increased to reduce the thermal expansion mismatch between the tungsten and copper-based material [7]; this is achieved by shaping the interlayer so that it is more thermally resistive where required, often generating spokes-like shape, (2) Compliant interlayer: partial structural decoupling the armour from the cooling pipe by adding some compliance to the interlayer, with spokes for instance, so that the stress caused by the thermal expansion mismatch is not fully transferred to the cooling pipe and (3) Heat flux redistribution: encouraging the heat flux to distribute more evenly around the cooling pipe thus evening out the thermal stresses over a larger area; this is achieved by strategic shaping of either the interlayer or the tungsten armour.

To assess the potential of a design idea, Design of Experiment (DoE) data were generated with the FEA software. These DoE data consist of solving the simulation for a wide range of all design parameters. These DoE produce large tables of data that can be difficult and time consuming to analyse.

To assist with this design space exploration, software was written to automatically generate and plot surface responses from the DoE data. Response surfaces are generated using cubic spline interpolation. This script, written in python, enabled each design family to be visualised on a single picture file which contains a response surface for each of the design criteria. An example of this file, for the final design, is shown in Figure 27 in Appendix $C$. 
This method enabled numerous designs to be screened and analysed rapidly. The best design within a design family as well as the limitations for each family could easily be identified and taken into consideration for the subsequent design iteration.

\section{Design concepts explored}

The design that was used for WPDIV phase 1 is shown in Figure 3. For the phase 1 design, the interlayer was made of two parts, the inner part was a continuous copper cylinder that was brazed to the cooling pipe prior to being machined with the axial grooves. The second part of the interlayer was a thin copper layer that was cast on the inside face of tungsten. The component was finally assembled by a second brazing operation to joint both part of the interlayer.

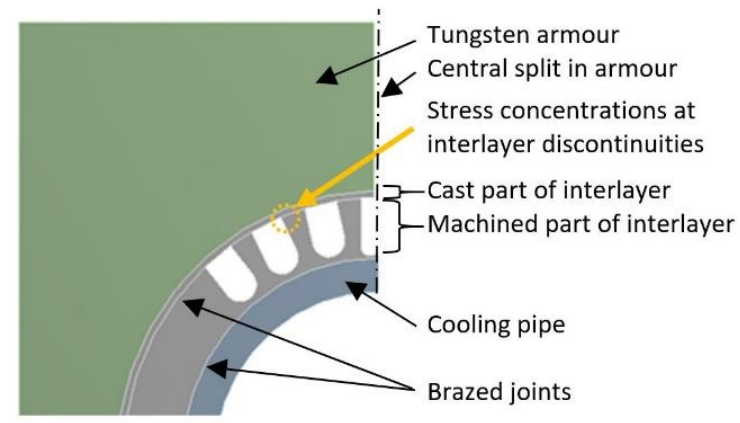

Figure 3: characteristic section of phase 1 design.

The advantage of the manufacturing method used on the phase 1 design were that most of the interlayer was continuous hence creating an integral buffer between the tungsten armour and the cooling pipe. The issues of this manufacturing method were that 2 brazing cycles were required (hence increasing the likelihood of defects), and that stress concentrations were created at the end of the spokes features (as indicated in Figure 3). Following high heat flux testing of phase 1 design mock-ups, both issues were identified as the dominant damage modes [6].

To produce the phase 2 design, a total of 16 design families have been explored; in this paper the 6 most accomplished are reported and discussed.

A description of each design family together with figures showing typical modelled geometries are as follows.

(a). This concept is used as the reference design, it has similar features as the thermal break phase 1 design [4] but with the updated dimensional constraints for phase 2 : cooling pipe inner diameter and thickness increased from $10 \& 1 \mathrm{~mm}$ to 12 \& $1.5 \mathrm{~mm}$; tungsten blocks radial width increased from 22 to $23 \mathrm{~mm}$ and the thickness of the plasma facing part of the tungsten armour increased

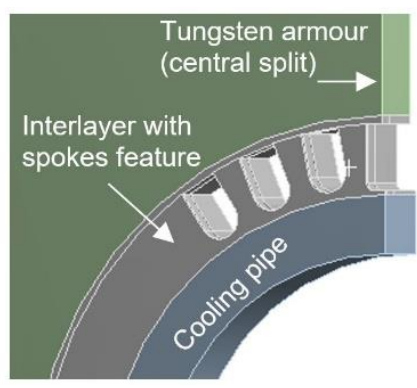

Figure 4: characteristic section for design family (a). from 5 to $8 \mathrm{~mm}$. The interlayer is made of an axially continuous pipe, concentric to the cooling pipe, in which $1 \mathrm{~mm}$ wide radial grooves are machined; the interlayer is brazed on one side to the cooling pipe and the other side to the thin copper strip that is cast in the tungsten armour. Two sets of results were generated using this concept with the axial width of the tungsten block set subsequently to $4 \mathrm{~mm}$ and $12 \mathrm{~mm}$. (b). This design has an axially discontinuous interlayer; each of the interlayer pieces have the same width as tungsten block, thus enabling the entire interlayer to be cast inside the tungsten armour with flush faces. This fully cast (rather than brazed) interlayer has two advantages, first it removes one of the brazing operations, second, because it is narrower, it enables more intricate machining

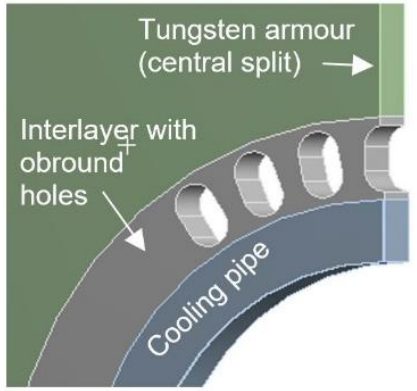

Figure 5: characteristic section for design family (b). than can be achieved using end-milling of axial grooves, as used in the phase 1 design (with the use of Electrical Discharge Machining). The Interlayer is shaped with $1 \mathrm{~mm}$ wide obround holes, $11^{\circ}$ apart to form spokes. The purpose of the obround holes is to remove the discontinuity, and stress concentration, at the outer end of the spokes. Two sets of results were also generated using this concept with the axial width of the tungsten block set subsequently to $4 \mathrm{~mm}$ and $12 \mathrm{~mm}$.

(c). This concept is similar to (b) apart from the first $0.4 \mathrm{~mm}$ inner part of the interlayer was made continuous axially, along the cooling pipe; as can be seen in the insert image of Figure 6. This continuous section shifts the stress concentration produced by the discontinuous tungsten / interlayer assemblies from the cooling pipe to the interlayer. This continuous section could be

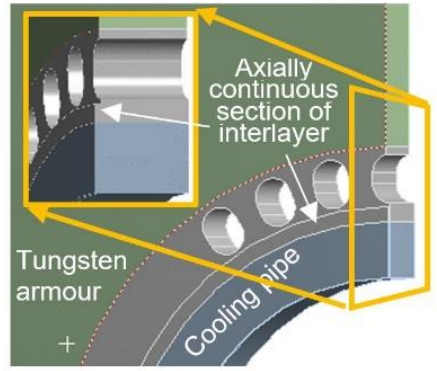

Figure 6: characteristic section for design family (c). manufactured by having part of the copper protruding slightly out of the tungsten block during the casting process; this $0.4 \mathrm{~mm}$ cylinder could then be machined from the cast copper and each block assembly could be brazed together to form the continuous section. Two sets of results were also generated using this concept with the axial width of the tungsten block set subsequently to $4 \mathrm{~mm}$ and $12 \mathrm{~mm}$.

(d). Identically to (c), the interlayer is axially discontinuous, with the same width as tungsten block, except the first $0.4 \mathrm{~mm}$ inner part which was made continuous along the cooling pipe. The tungsten block was split in two symmetrical locations through its armour thickness with the aim to re-direct the heat flux towards the outer part of the cooling pipe. The end of the split was stress

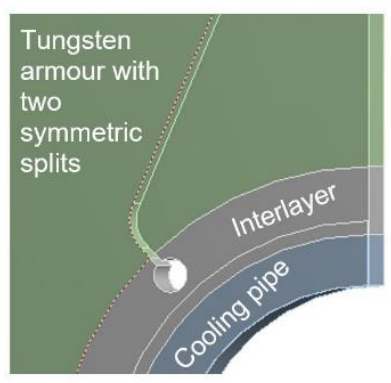

Figure 7: characteristic section for design family (d). relieved using a hole made in the interlayer. The axial width of the tungsten block was $4 \mathrm{~mm}$. 
(e). This concept attempts to combine the advantage of the thermal break concept (c) (but with easier-to-manufacture circular holes), together with the heat flux redirecting idea in (d). The lower position of the split was fixed and relieved in one of the circular holes. The axial width of the tungsten block was at $4 \mathrm{~mm}$.

(f). The overall shape of the interlayer is identical to (c), (d) and (e); however, the Interlayer was shaped with $0.5 \mathrm{~mm}$ wide and angled obround holes, $\left(9^{\circ}\right.$ apart) to form spokes. The idea is to provide additional compliance and thermal break to the interlayer while shifting the heat flux towards the outside of the cooling pipe. This concept

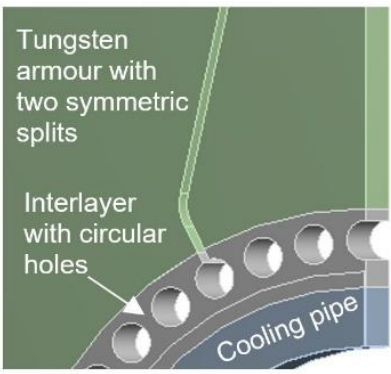

Figure 8: characteristic section for design family (e).

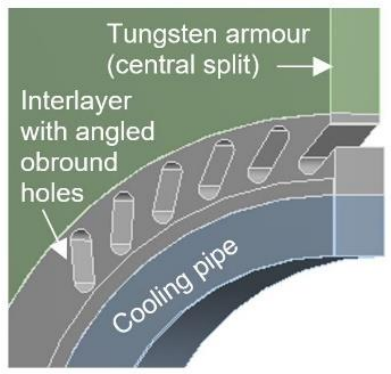

Figure 9: characteristic section for design family (f). also reverts to having central armour split, which may be advantageous for operational reasons, as a total failure of the interlayer would keep the armour captive (contrary to concept (d) and (e)). The axial width of the tungsten block was $12 \mathrm{~mm}$.

Table 3 shows the parameters and range that was being explored together with the total number of models that were solved for the DoE.

\begin{tabular}{|c|c|c|}
\hline $\begin{array}{c}\text { Design } \\
\text { family ref. }\end{array}$ & Varying design parameters and [range] & $\begin{array}{c}\text { DoE } \\
\text { sample size }\end{array}$ \\
\hline a & $\begin{array}{c}\text { (1)-Number of spokes [0 to } 15] \\
\text { (2)-Interlayer Thickness [0.8 to } 3.0 \mathrm{~mm} \text { ] }\end{array}$ & 135 \\
\hline$b$ & $\begin{array}{c}\text { (1)-Number of spokes [0 to 15] } \\
\text { (2)-Interlayer Thickness [1.5 to } 3.5 \mathrm{~mm} \text { ] }\end{array}$ & 117 \\
\hline c & $\begin{array}{c}\text { (1)-Number of spokes [0 to } 15] \\
\text { (2)-Interlayer Thickness [1.5 to } 3.5 \mathrm{~mm} \text { ] }\end{array}$ & 117 \\
\hline d & $\begin{array}{l}\text { (1)-Slot lower dist. from centre [1 to } 8.5 \mathrm{~mm} \text { ] } \\
\text { (2)-Slot upper dist. from centre [0.5 to } 10 \mathrm{~mm} \text { ] }\end{array}$ & 64 \\
\hline e & $\begin{array}{l}\text { (1)-Number of holes [0 to } 6 \mathrm{~mm} \text { ] } \\
\text { (2)-Slot upper dist. from centre [0.5 to } 10 \mathrm{~mm} \text { ] }\end{array}$ & 56 \\
\hline$f$ & $\begin{array}{c}\text { (1)-Number of spokes [0 to } 19] \\
\left.\text { (2)-Spokes angle from horizontal [0 to } 45^{\circ}\right]\end{array}$ & 117 \\
\hline
\end{tabular}

Table 3: List of varying design parameters and DoE sample size for each design family. The number of spokes reported $(n)$ are for the F.E.

quarter block; on the full mock-up the total number of spokes is $2 n$,

which account for the symmetry and the upper central groove.

\section{Results}

\subsection{Response Surfaces}

This section displays some of the response surfaces for each of the concepts that are defined in Section 3. These response surfaces have been generated using the procedure defined in section 2.4 .

For all concepts, only the response surfaces for the four most significant criteria (as described in section 5) are show from Figure 10 through to Figure 18. For concept (c) with a $12 \mathrm{~mm}$ wide tungsten armour, the surface responses for all the criteria are shown in Figure 27 in Appendix C. Areas that are out of specification (as per Table 2) are highlighted in orange.
Note that the criterion that each response surface refers to is referenced by its name and its reference letter (from Table 2 ) in square brackets in the plot title. When a criterion needs to be assessed against both the heat-load and the standby load steps, both surface responses are plotted.

For example, Figure 10 bottom left shows the peak temperature in the interlayer (optimisation criterion $\mathrm{F}$ ) varying from 600 to $960^{\circ} \mathrm{C}$, as a function of the interlayer thickness (horizontal axis) and the number of spokes (the vertical axis); values above the $885^{\circ} \mathrm{C}$ design limit are highlighted towards the upper right of the plot.

The red stars represent the location of the 10 selected designs which are discussed in section 6 .
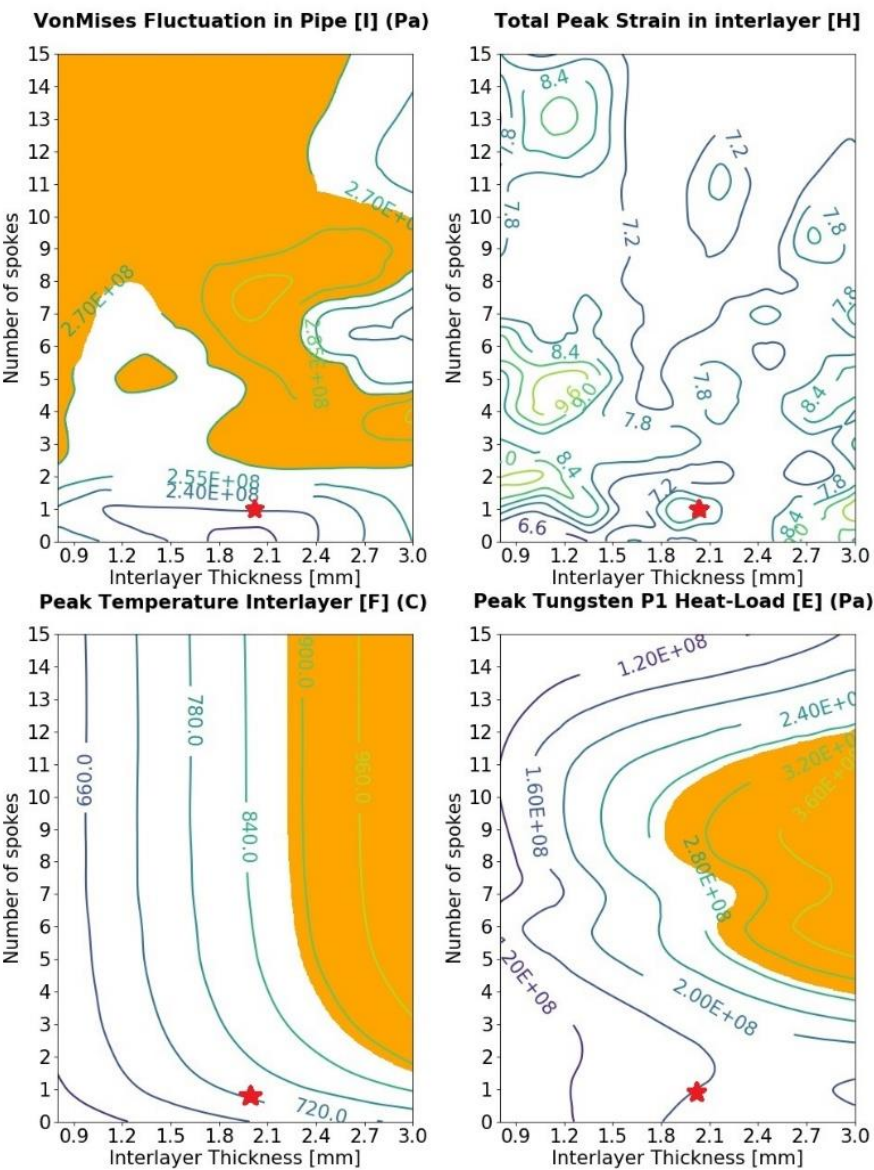

Figure 10: Selection of response surfaces for concept (a) with $4 \mathrm{~mm}$ wide tungsten block. 
VonMises Fluctuation in Pipe [l] $(\mathrm{Pa})$
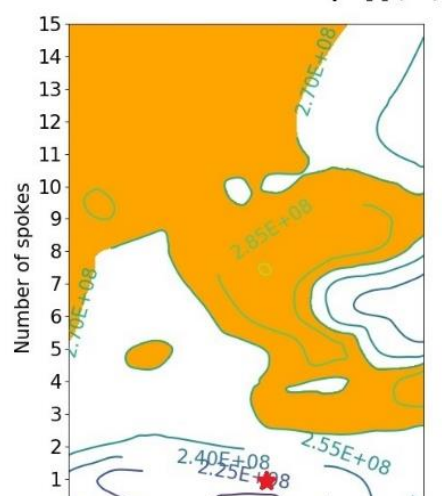

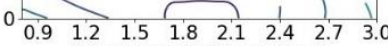
Interlayer Thickness [mm]

Peak Temperature Interlayer [F] (C)
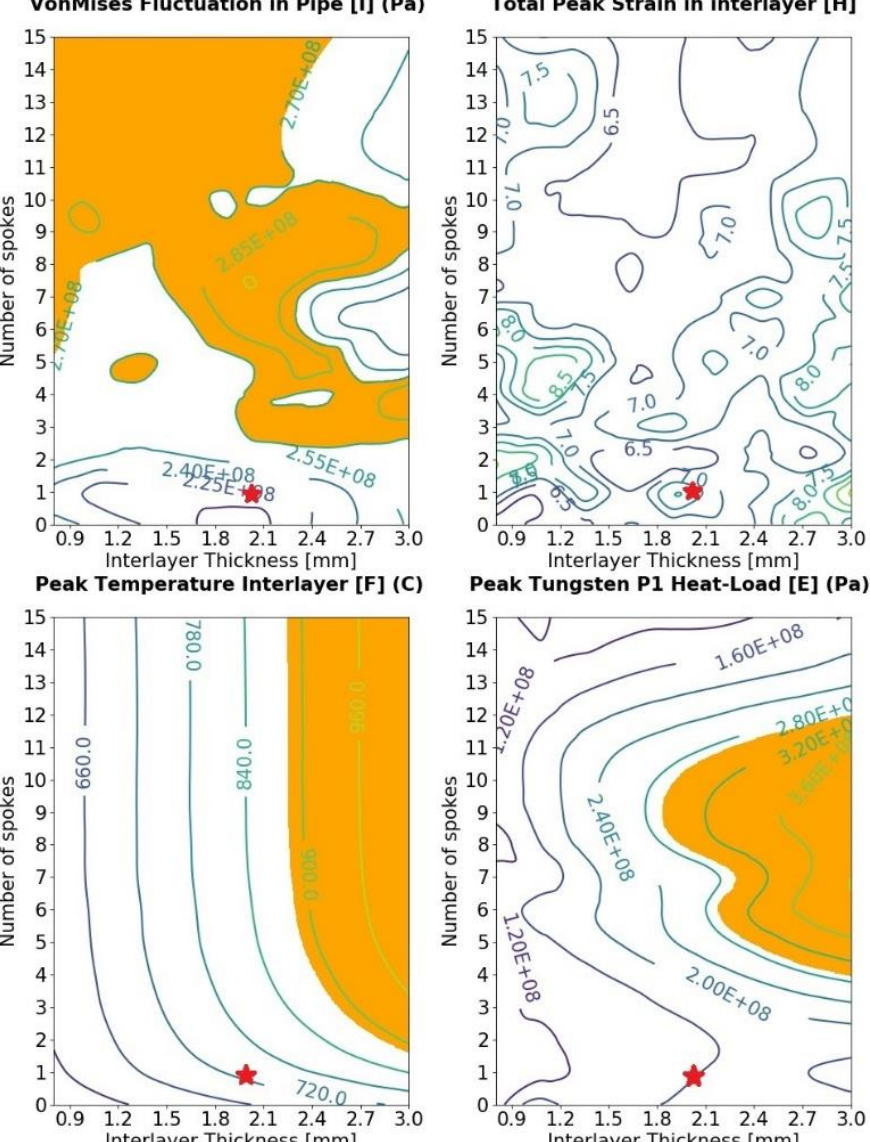

$\begin{array}{lllllllllll}0 & 0.9 & 1.2 & 1.5 & 1.8 & 2.1 & 2.4 & 2.7 & 3.0\end{array}$ Peak Tungsten P1 Heat-Load [E] (Pa)

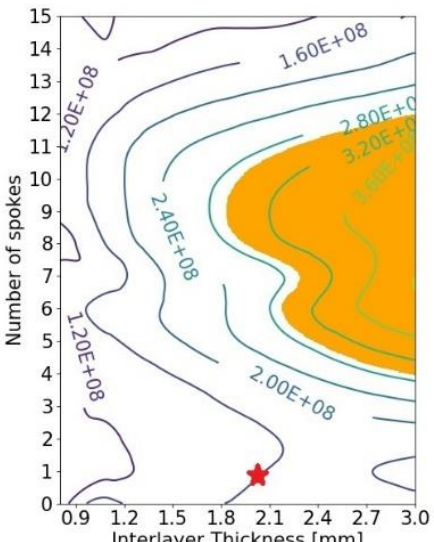
Interlayer Thickness [mm]

Figure 11: Selection of response surfaces for concept (a) with $12 \mathrm{~mm}$ wide tungsten block.
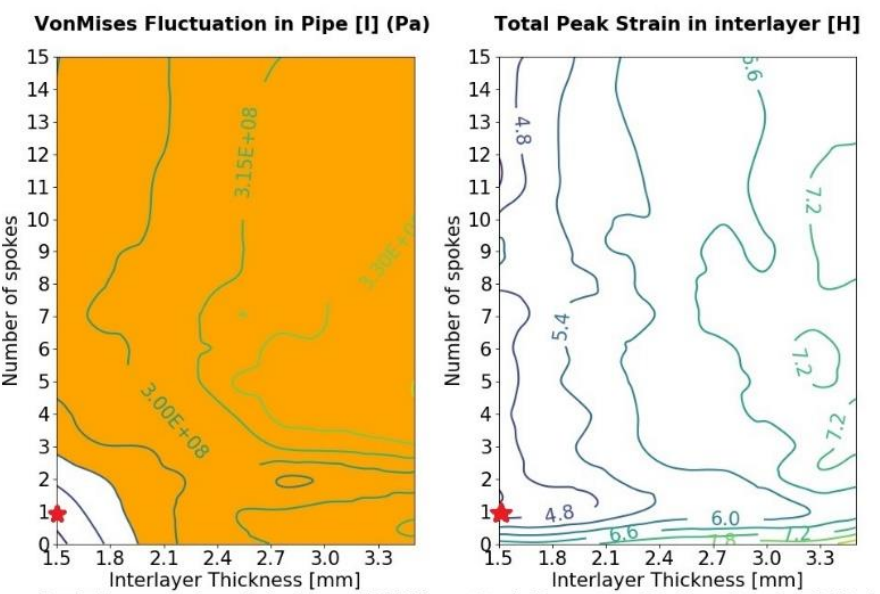

Peak Temperature Interlayer [F] (C)
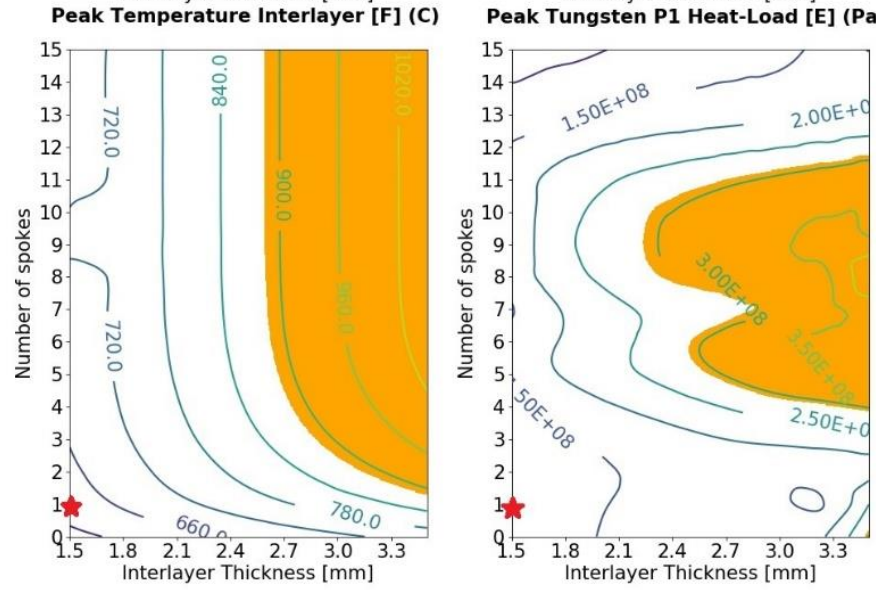

Figure 12: Selection of response surfaces for concept (b) with $4 \mathrm{~mm}$ wide tungsten block.
VonMises Fluctuation in Pipe [I] $(\mathrm{Pa})$

Total Peak Strain in interlayer $[\mathrm{H}]$

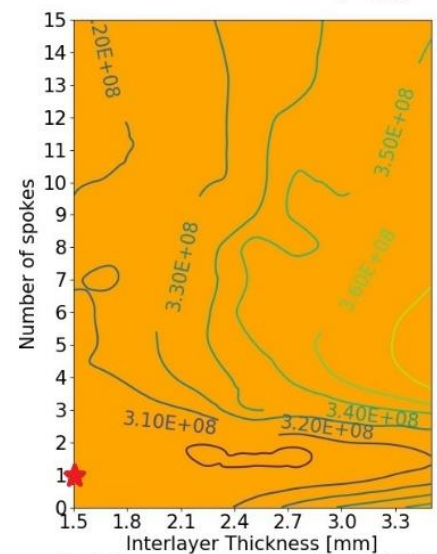

Peak Temperature Interlayer [F] (C)
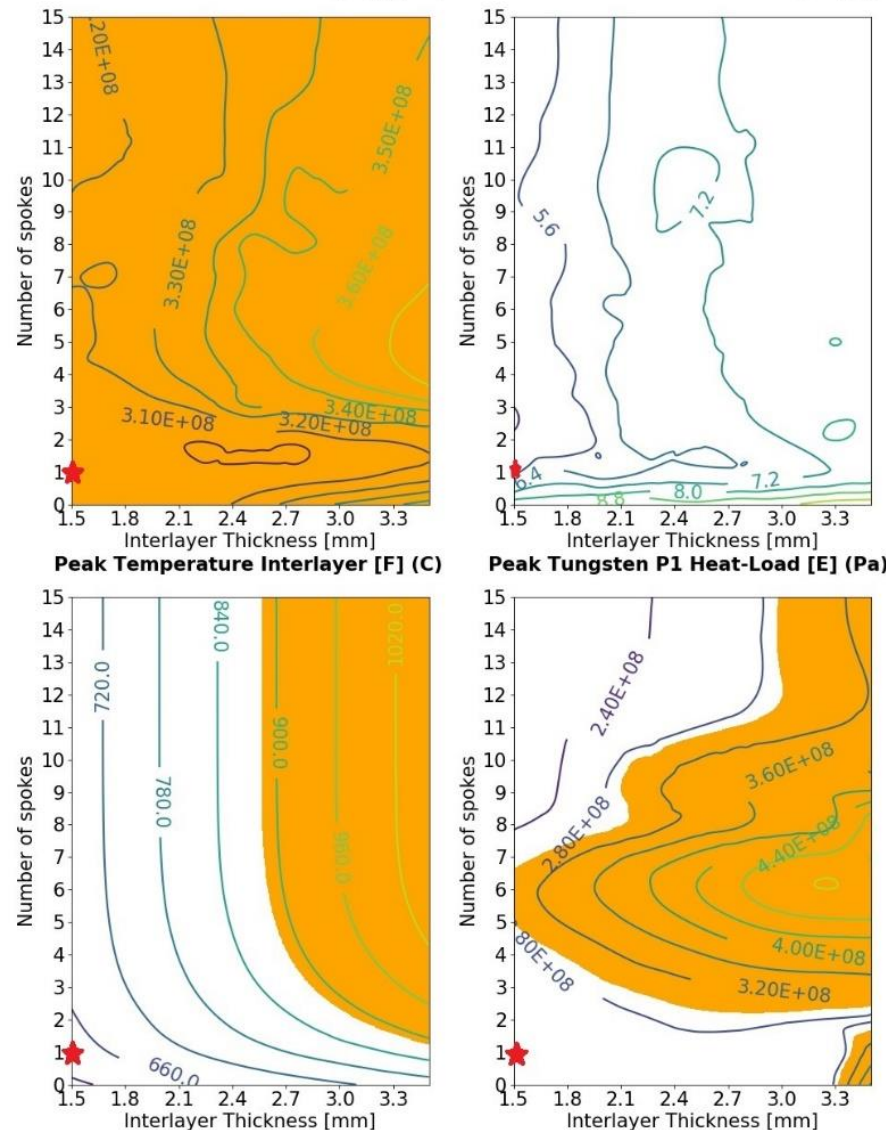

Figure 13: Selection of response surfaces for concept (b) with $12 \mathrm{~mm}$ wide tungsten block.

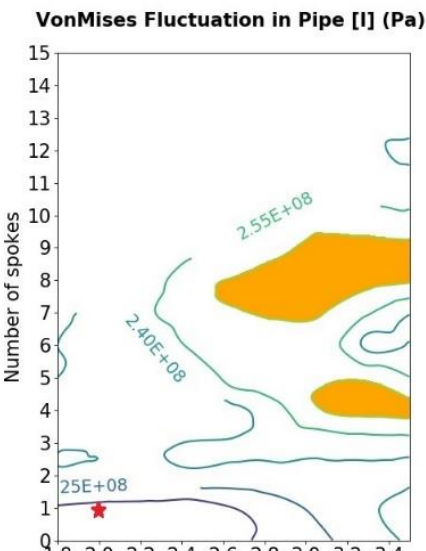

$\begin{array}{llllllllll}1.8 & 2.0 & 2.2 & 2.4 & 2.6 & 2.8 & 3.0 & 3.2 & 3.4\end{array}$

Peak Temperature Interlayer [F] (C)

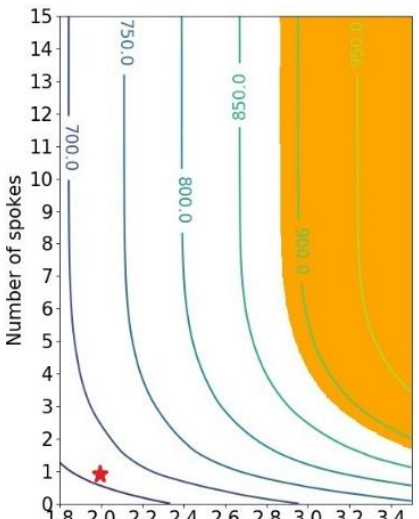

Interlayer Thickness [mm]
Total Peak Strain in interlayer $[\mathrm{H}]$

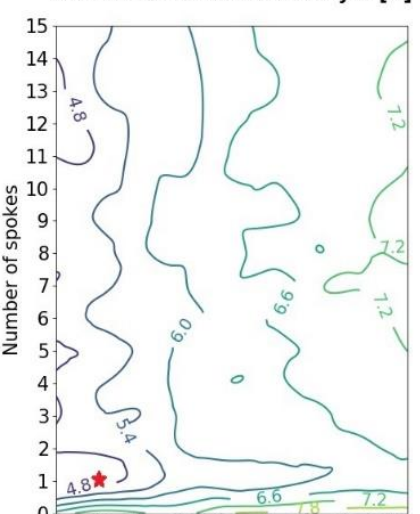

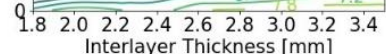

Peak Tungsten P1 Heat-Load [E] (Pa)

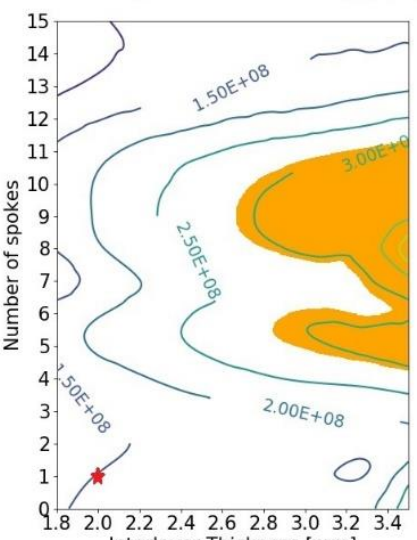

Figure 14: Selection of response surfaces for concept (c) with $4 \mathrm{~mm}$ wide tungsten block. 


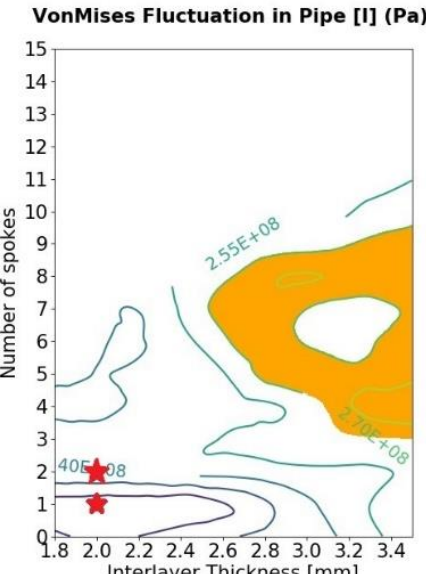

Interlayer Thickness [mm]
Peak Temperature Interlayer [F] (C)

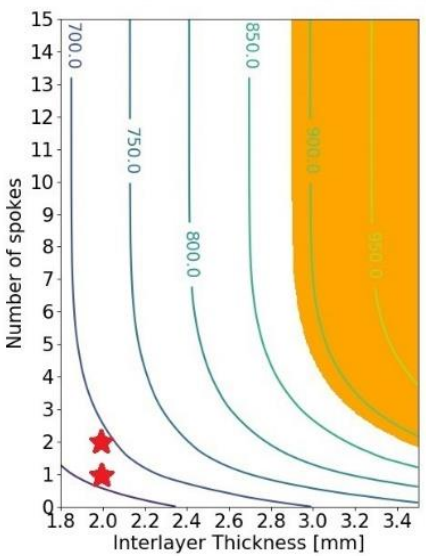

Figure 15: Selection of response surfaces for concept (c) with $12 \mathrm{~mm}$ wide tungsten block.
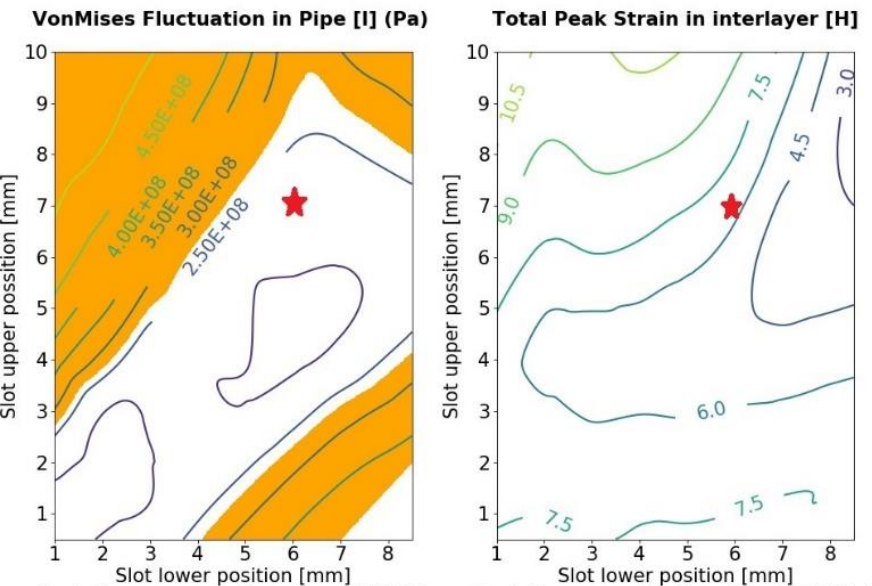

Peak Temperature Interlayer [F] (C)
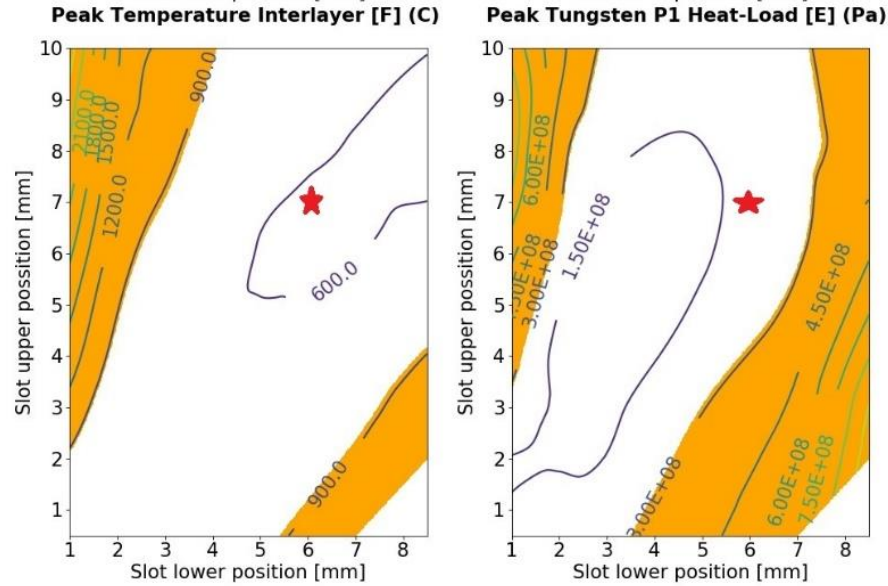

Figure 16: Selection of response surfaces for concept (d).
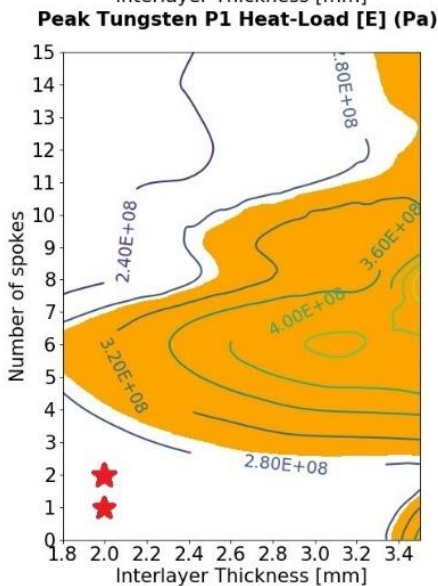
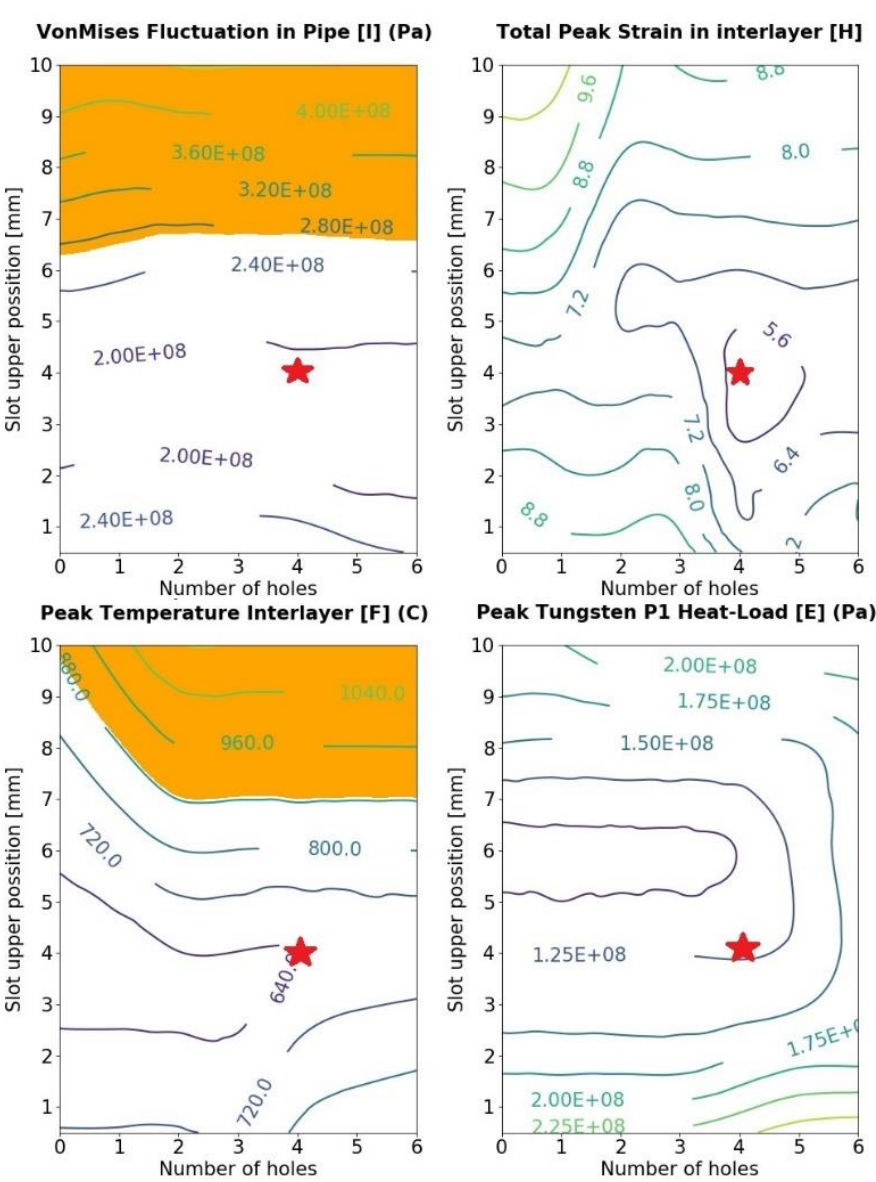

Figure 17: Selection of response surfaces for concept (e).
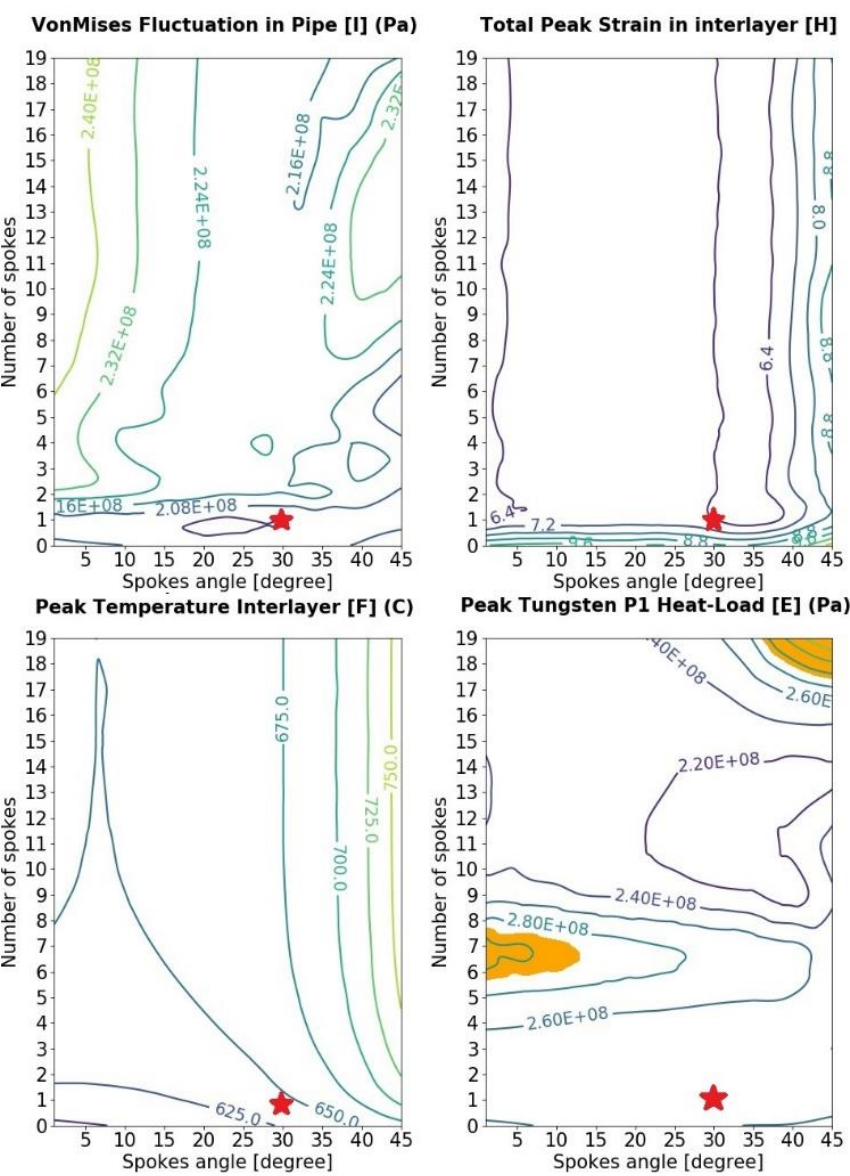

Figure 18: Selection of response surfaces for concept (f). 


\section{Discussion}

From studying all response surfaces in details, it was found that four criteria were the limiting factors of most concepts; they are: (1) The von Mises fluctuation in the pipe, (2) the total strain in the interlayer, (3) the peak temperature on the interlayer and (4) the peak first principal stress in the tungsten. These criteria form the bases for the discussion for most concepts; other criteria are referred to if relevant to a set of result.

\section{Concept (a), based on phase 1 design}

Recall that concept (a) is based on the phase 1 design with the updated geometric constraints for phase 2 ; the explored parameters were the interlayer thickness and the number of spokes. On phase 1 design, the strain in the interlayer was $4.0 \%$ (when solved with the same boundary condition and load). In this design family the interlayer strain increased significantly, with a minimum of 6.6\% (Figure 10).

\section{Increasing tungsten width to $12 \mathrm{~mm}$}

Within the EUROfusion WPDIV group and for phase 2, the preferred axial thickness for the tungsten was $12 \mathrm{~mm}$. However, for phase 1 and for some of the concepts explored here, this thickness was $4 \mathrm{~mm}$. Concepts (a), (b) and (c) were solved iteratively with both thicknesses. The results displayed from Figure 10 through to Figure 15 show that criteria are only marginally affected by this change of dimension.

\section{Reducing stress concentration in interlayer}

Concept (b) attempts to remove the stress concentration that is present in concept (a), at the discontinuity of the spoke ends (Figure 3). Results for concept (b), summarised in Figure 12 and Figure 13, show that this alteration decreases significantly the strain in the copper interlayer, compared to (a), from a minimum of $6.6 \%$ on design (a) to $4.8 \%$ here. However, in concept (b), the fluctuating von Mises on the pipe is much higher than on concept (a) and mostly above specification. This is caused by the now discontinuous interlayer which creates a stress concentration at its base onto the cooling pipe, between tungsten/copper blocks.

\section{Reducing stress concentration on cooling pipe}

As described in section 3, concept (c) is constructed by making the first $0.4 \mathrm{~mm}$ inner part of the interlayer continuous axially, along the cooling pipe. Results for this concept are shown in Figure 14 and Figure 15. This addition is very effective at reducing the fluctuating stress concentration on the cooling pipe; the large area of the design space that was above the design limit in concept (b) has considerably contracted. Furthermore, other criteria are not significantly affected.

\section{Dual armour split}

The effect of the two symmetric splits in the armour of concept (d) is twofold. First, as described in Section 3, they artificially re-direct the heat flux more evenly around the cooling pipe hence reducing thermal stresses; second, they reduce the fluctuating stress in the cooling pipe by reducing the pipe wall bending caused by the central tungsten split; this effect is explained below.

High pipe wall bending stress was noticed in previous designs at the location of the central tungsten split and is illustrated in Figure 19 below. Pipe stresses are typically dominated by axial and hoop stresses; radial stresses being very small. Axial stresses are mostly caused by the thermal field imposed on the cooling pipe, where the upper part is hotter than the lower part; which when restrained creates compressive and tensile stress on the upper and lower part of the pipe respectively. Hoop stresses are dominated by a bend in the pipe wall below the armour split; this is seen clearly on the upper right picture of Figure 19. The origin of this pipe wall bending becomes evident when the temperature distribution from the full model is applied to a model where the interlayer has been removed (Figure 19 right lower picture); visibly this pipe wall bending is caused by the deformation mode of the tungsten block that pushes the top of the cooling pipe.
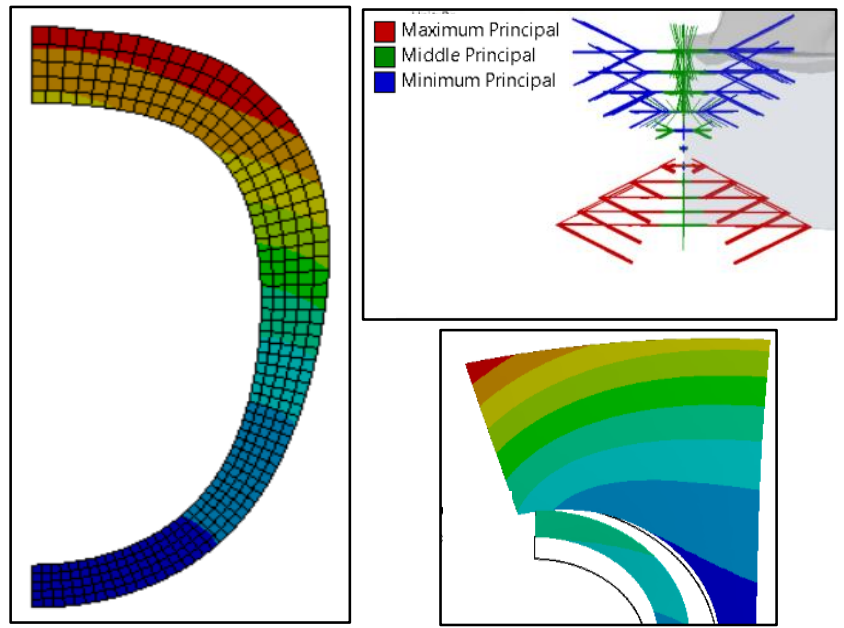

Figure 19: Deformation and principal stress vectors on the cooling pipe for a design (a) with central armour split. 200 times amplified deformation of the cooling pipe is shown on the left; principal stresses are shown on the axial face of the cooling pipe on the top right picture. The lower right picture shows a 30 times amplified deformation of the tungsten and cooling pipe solved with the interlayer removed but under the thermal field from the full model.

Consequently, by removing the central armour split and replacing it by two symmetric splits, this deformation mode should be reduced, hence attenuating this pipe wall bending stress. Concept (d) implements this modification; the best results from this design family is obtained with a lower and upper slot position of $6 \mathrm{~mm}$ and $7 \mathrm{~mm}$ respectively (Figure 16).

\section{Dual armour split and thermal break}

Concept (e) aims to combine the improvement obtained by the dual armour split with that of the thermal break. To facilitate manufacturing, holes in the interlayer were made circular. The best result from this set is a design with 4 holes and $4 \mathrm{~mm}$ upper slot position (Figure 17); the fluctuating stress in the tungsten is lower than on any other concepts at under 200MPa (Table 8).

\section{Angled and thinner grooves and spokes}

For concept (f), the preferred design is with a single spoke that is angled at $30^{\circ}$ (Figure 18). This design point yields the minimum values, within this concept, for both the interlayer strain and the fluctuating stress in the cooling pipe.

\section{Design selection}

Based on the response surfaces, a list of 10 of the most promising designs was produced; these are marked on the response surfaces plots, in section 4.1, with a red star; for some concepts several designs, with different attributes, were selected. The selection aimed primarily at minimising the four most limiting criteria, as described in section 5 . Performance results for this down-selected list are shown in Table 8 in Appendix C, and compared on a radar chart in Figure 20. 


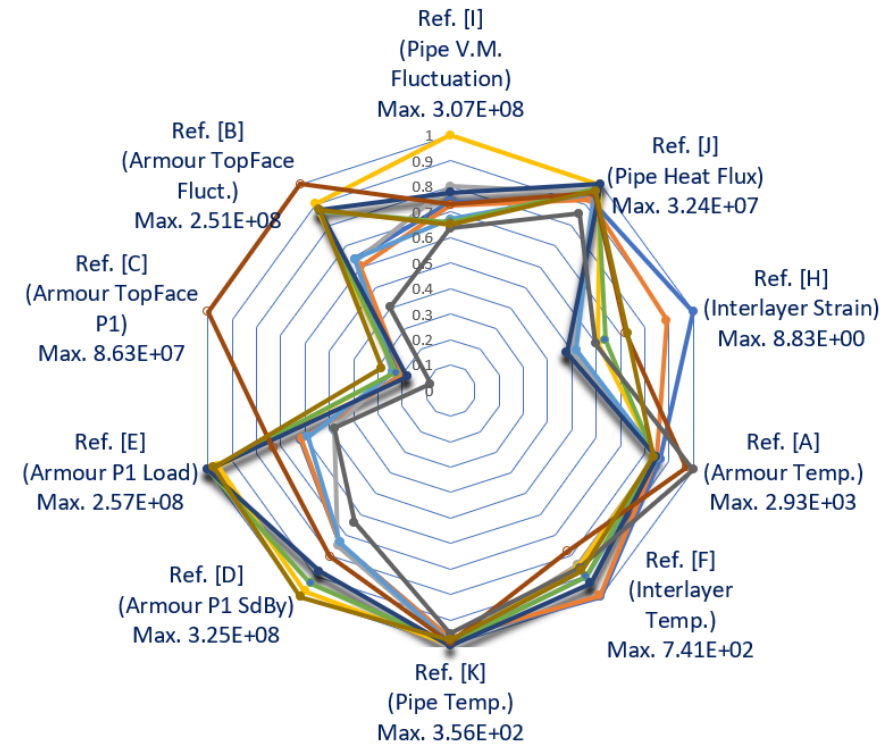

-Concept (a) with: $4 \mathrm{~mm}$ wide tungsten; $2.0 \mathrm{~mm}$ interlayer \& 1 spoke $\rightarrow$ Concept (a) with: $12 \mathrm{~mm}$ wide tungsten; $2.0 \mathrm{~mm}$ interlayer; \& 1 spoke $\rightarrow$ Concept (b) with: $4 \mathrm{~mm}$ wide tungsten; $1.5 \mathrm{~mm}$ interlayer \& 1 spoke $\leadsto$ Concept (b) with: $12 \mathrm{~mm}$ wide tungsten; $1.5 \mathrm{~mm}$ interlayer \& 1 spoke $\rightarrow$ Concept (c) with: $4 \mathrm{~mm}$ wide tungsten; $2.0 \mathrm{~mm}$ interlayer $\& 1$ spoke $\rightarrow$-Concept (c) with: $12 \mathrm{~mm}$ wide tungsten; $2.0 \mathrm{~mm}$ interlayer \& 1 spoke $\rightarrow$ Concept (c) with: $12 \mathrm{~mm}$ wide tungsten; $2.0 \mathrm{~mm}$ interlayer \& 2 spoke $\rightarrow$ Concept (d) with: $6.0 \mathrm{~mm}$ lower $\& 7 \mathrm{~mm}$ upper slot position

$\rightarrow$ Concept (e) with: 4 holes \& $4 \mathrm{~mm}$ upper slot position

$\rightarrow$ Concept (f) with: $30^{\circ} \& 1$ spokes

Figure 20: Chart comparing the performance of the most promising designs against each design criterion. Criteria are normalised and referenced by capital letter as specified in Table 2 . The selected design is circled in red in the legend.

The design based on concept (c) with a $2.0 \mathrm{~mm}$ thick interlayer and 2 spokes (per half model) was selected as the second phase design. This design minimises the interlayer strain (which was thought to be responsible for mock-up failures in phase 1 ) and on-balance it performs well on all other criteria. This final design is illustrated in Figure 21.

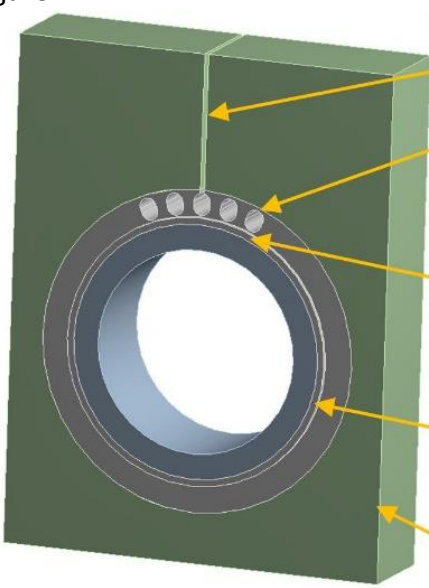

Features:

- Centrally split tungsten block through the armour thickness.

$2.0 \mathrm{~mm}$ Interlayer partially continuous axially to reduce stress concentration on cooling pipe.

- Interlayer shaped with $1 \mathrm{~mm}$ wide obround holes, $11^{\circ}$ apart to form spokes whilst minimising stress concentration.

- Copper interlayer casted inside tungsten block to reduce brazing operation.

Axial width of the tungsten block set to $12 \mathrm{~mm}$.

Figure 21: Model of the selected design showing specific features.

For this definitive design, the results extracted from the response surfaces were verified by simulating the selected geometry on a standalone F.E. model. The comparison between the two set of results (shown in Appendix C, Table 9 and Figure 28) are in close agreement, the largest discrepancy is $11 \%$ for the interlayer strain and all other results are within $2 \%$.

\subsection{Enhancement from phase 1 design}

The performance of the selected phase 2 design is compared to that of the phase 1 design in Figure 22. Despite the more challenging geometric constraints, on all criteria but one, this design performs better or similarly to that of the first phase. The comparison suggests
$20 \%$ reduction in cycling stress in the cooling pipe and a $28 \%$ reduction in the interlayer strain, this latter parameter was the dominant damage mode in the phase 1 tests. The only criterion that is worse is the peak temperature on the tungsten. The increase is due to the change in armour thickness from 5 to $8 \mathrm{~mm}$ (an imposed constraint for phase 2 designs) which raises the thermal impedance between the cooling pipe and the surface that receives the heat flux, thus inevitably increasing the peak temperature of the latter.

The selected design was taken forward for mock-up manufacturing and high heat flux testing [6]. So far, the phase 2 mock-up remained undamaged after the fatigue test consisting of 500 cycles at $20 \mathrm{MW} / \mathrm{m}^{2}$ whereas phase 1 mock-ups showed significant deterioration [6].

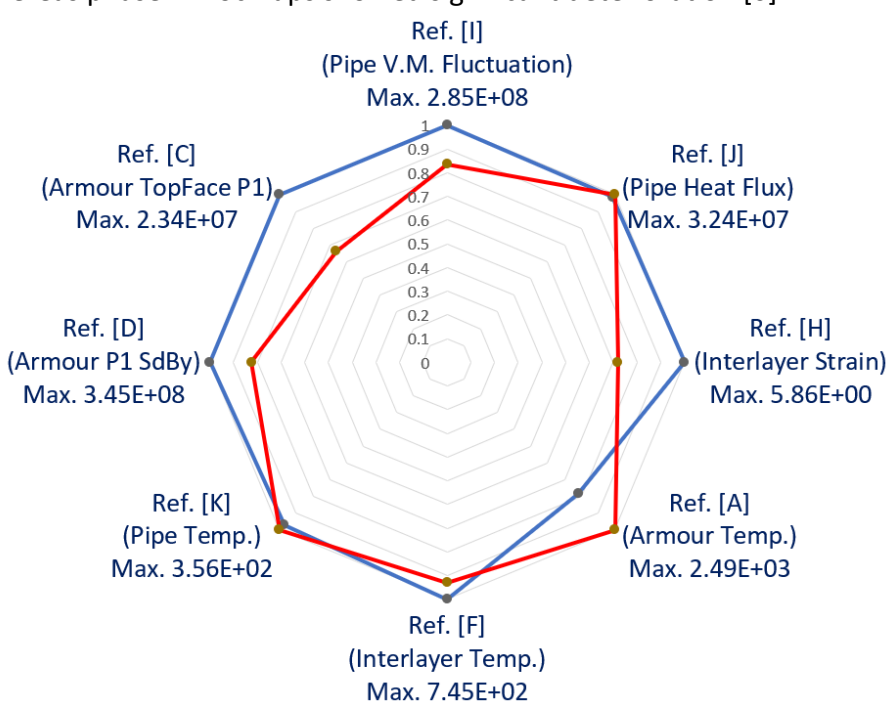

$\rightarrow$ Phase 1 Design $\quad$-Opt_5_12mm Phase 2 Design

Figure 22: Radar chart comparing the normalised performance of the selected phase 2 design to that of phase 1 .

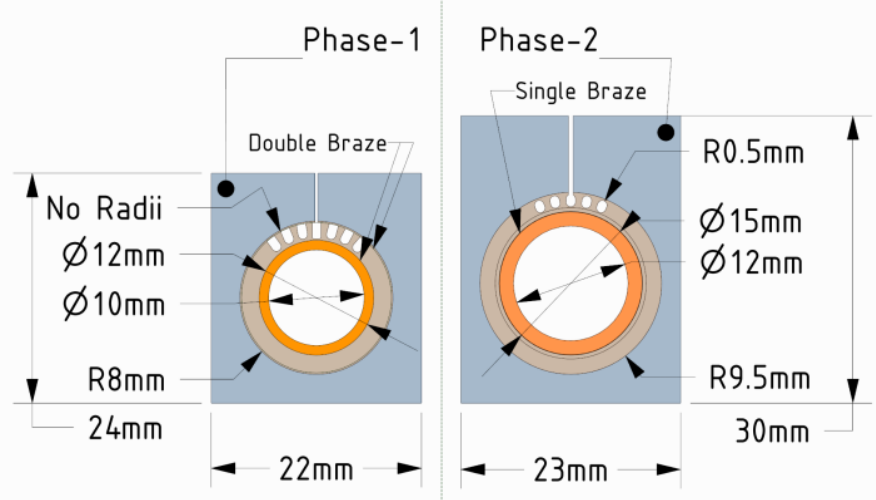

Figure 23: Geometric comparison between designs of phase 1 and phase 2.

\section{Conclusion}

During this second phase DEMO divertor target project, a balanced and well-performing mock-up design was generated using the principles of the thermal break, compliant interlayer and heat flux redistribution. To achieve the objective, design optimisation techniques were used extensively together with a bespoke software enabling efficient data processing and rapid visualisation of the design space.

The second phase design was selected after exploring sixteen concepts and comparing results from the most promising designs. Despite more challenging geometric constraints, this design is predicted to perform significantly better than that of the first phase. 
Four mock-ups of the selected design were manufactured [6] and have to date successfully passed a series of high heat flux testing, including 500 cycles at $20 \mathrm{MW} / \mathrm{m}^{2}$.

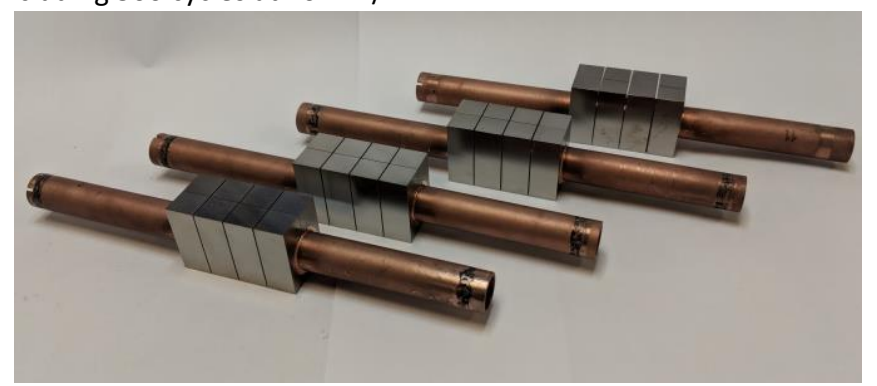

Figure 24: The 4 mock-ups that were fabricated to the selected phase 2 design.

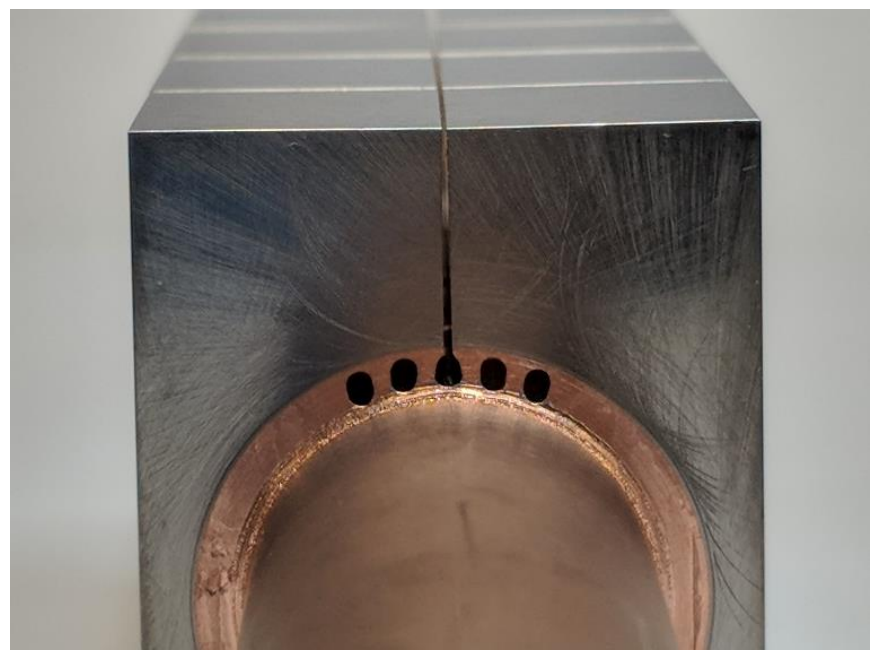

Figure 25: Fabricated mock-up showing the interlayer features.

\section{Acknowledgments}

This work has been carried out within the framework of the EUROfusion Consortium and has received funding from the Euratom research and training programme 2014-2018 and 2019-2020 under grant agreement No 633053, and from the RCUK Energy Programme [grant number EP/1501045]. To obtain further information on the data and models underlying this paper please contact PublicationsManager@ccfe.ac.uk. The views and opinions expressed herein do not necessarily reflect those of the European Commission.

\section{References}

[1] J. You et al, «Conceptual design studies for the European DEMO divertor: Rationale and first results, » Fusion Engineering and Design, vol. 109-111 Part B, pp. 1598-1603, November 2016.

[2] J. You et al, «European divertor target concepts for DEMO: Design rationales and high heat flux,» Nuclear Materials and Energy, vol. 16, pp. 1-11, August 2018.
[3] T. Hirai and al, "ITER full tungsten divertor qualification program and progress," Physica Scripta, p. 014006, 2014.

[4] M. Fursdon et al, "The development and testing of the thermal break divertor monoblock target design delivering 20 MW/m2 heat load capability,» Phys. Scr., vol. T170, p. 014042, 2017.

[5] H. Greuner et al, «High heat flux facility GLADIS: Operational characteristics and results of W7-X pre-series target tests, " Journal of Nuclear Materials, vol. 367370 part B, pp. 14441448, August 2007.

[6] A. Lunkenskas et al, «High heat flux test results for a thermal break demo divertor target and subsequent design and manufacturing development," Fusion Engineering and Design, March 2019.

[7] T. Barrett and al, "Virtual Engineering of a Fusion Reactor: Application to Divertor Design, Manufacture, and Testing," IEEE Transactions on Plasma Science, 2019.

[8] T. Barrett et al, «Enhancing the DEMO divertor target by interlayer engineering, " Fusion Engineering and Design, vol. 98 99, pp. 1216-1220, October 2015.

[9] Y. Jeong-Ha and al, "Novel Materials and Advanced Design Concepts for DEMO Divertor Targets," in CIMTEC, Perugia, 2018.

[10] M. Fursdon, J.-H. You, T. Barrett and M. Li, "A hybrid analysis procedure enabling elastic design rule assessment of monoblock-type divertor components," Fusion Engineering and Design, pp. 154-164, 2018.

[11] M. Li and J.-H. You, "Interpretation of the deep cracking phenomenon fo tungsten monoblock targets observed in highheat-flux fatigue tests at 20MW/m2," Fusion Engineering and Design, 2015.

[12] M. Fursdon, "Towards reliable design justification by analysis for plasma facing components - guidelines for inelastic assessment (part 1: unirradiated)," Fusion Engineering and Design, p. To be pubished.

[13] M. Missirlian et al, «The WEST project: PFC shaping solutions investigated for the ITER-like W divertor,» Fusion Engineering and Design, vol. 88, pp. 1793-1797, 2013.

[14] E. N. Sieder and G. E. Tate, "Heat transfer and pressure drop of liquids in tubes," Ind. Eng. Chem. 28 (12), p. 1429-1435, 1936.

[15] T. D. Marshall et al., "Modelling the Nukiyama curve for water-cooled fusion divertor channels Fusion Technology," Fusion Technol. 39, 2001

[16] U. W. Mszanowski, "Thermprop 5.2 A thermohydraulic properties program for heat transfer design evaluations based on the eupiter code version 4.2," EFDA, June 2006.

[17] ITER, SDC-IC Appendix A, Materials Design Limit Data V3.3, Ref: G 74 MA 8 01-05-28 W 0.2. 


\section{Appendix A: Material Properties}

Table 4 below displays the linear properties for the 3 materials and Table 5 \& Table 6 show the additional elasto-plastic parameters used for cuCrZr and Copper.

Table 4: Summary of material linear properties (taken from [17]):

\begin{tabular}{|c|c|c|c|c|c|c|}
\hline & $\begin{array}{c}\text { Temperature } \\
\left({ }^{\circ} \mathrm{C}\right)\end{array}$ & $\begin{array}{c}\text { Thermal Expansion } \\
\text { Coeff. }\left[1 /{ }^{\circ} \mathrm{C}\right]\end{array}$ & $\begin{array}{l}\text { Young's Modulus } \\
\text { [MPa] }\end{array}$ & $\begin{array}{c}\text { Thermal } \\
\text { Conductivity } \\
{[\mathrm{W} / \mathrm{Km}]}\end{array}$ & Poisson's ratio & Density $\left[\mathrm{Kg} / \mathrm{m}^{3}\right]$ \\
\hline \multirow{5}{*}{$\mathrm{CuCrZr}$} & 20 & $1.67 \mathrm{E}-05$ & 127500 & 318 & 0.33 & 8900 \\
\hline & 200 & 1.77E-05 & 123000 & 343 & 0.33 & 8816 \\
\hline & 400 & $1.81 \mathrm{E}-05$ & 113000 & 347 & 0.33 & 8716 \\
\hline & 600 & $1.86 \mathrm{E}-05$ & 95000 & 346 & 0.33 & 8665 \\
\hline & 900 & $1.86 \mathrm{E}-05$ & 86000 & 346 & 0.33 & 8665 \\
\hline \multirow{5}{*}{ Copper } & 20 & $1.683 \mathrm{E}-05$ & 117000 & 401 & 0.33 & 8940 \\
\hline & 200 & $1.758 \mathrm{E}-05$ & 110000 & 388 & 0.33 & 8854 \\
\hline & 400 & $1.822 \mathrm{E}-05$ & 98000 & 374 & 0.33 & 8744 \\
\hline & 600 & $1.881 \mathrm{E}-05$ & 81930 & 360 & 0.33 & 8612 \\
\hline & 1000 & $2.066 \mathrm{E}-05$ & 35180 & 334 & 0.33 & 8293 \\
\hline \multirow{9}{*}{ Tungsten } & 20 & $4.50 \mathrm{E}-06$ & 397800 & 172.8 & 0.29 & 19298 \\
\hline & 200 & $4.53 \mathrm{E}-06$ & 396400 & 155.5 & 0.29 & 19254 \\
\hline & 400 & 4.63E-06 & 392600 & 139.8 & 0.29 & 19204 \\
\hline & 600 & $4.72 \mathrm{E}-06$ & 386700 & 127.2 & 0.29 & 19152 \\
\hline & 1000 & $4.89 \mathrm{E}-06$ & 368400 & 110.5 & 0.29 & 19042 \\
\hline & 1500 & $5.13 \mathrm{E}-06$ & 333300 & 101.1 & 0.29 & 18895 \\
\hline & 2000 & $5.43 \mathrm{E}-06$ & 284600 & 99.1 & 0.29 & 18895 \\
\hline & 2500 & 5.84E-06 & 235900 & 98.9 & 0.29 & 18895 \\
\hline & 3000 & $6.40 \mathrm{E}-06$ & 235900 & 98.9 & 0.29 & 18895 \\
\hline
\end{tabular}

Table 5: Chaboche parameters for elasto-plastic kinematic hardening model of $\mathrm{CuCrZr}$ :

\begin{tabular}{|c|c|c|c|c|c|c|c|c|}
\hline & \multirow[b]{2}{*}{ Temperature $[\mathrm{C}]$} & \multicolumn{3}{|c|}{ Material } & \multirow{2}{*}{$\begin{array}{c}\text { Material } \\
\text { Constant C2 } \\
{[\mathrm{MPa}]}\end{array}$} & \multicolumn{3}{|c|}{ Material } \\
\hline & & $\begin{array}{c}\text { Yield Stress } \\
{[\mathrm{MPa}]}\end{array}$ & $\begin{array}{c}\text { Constant C1 } \\
\text { [MPa] }\end{array}$ & $\begin{array}{c}\text { Material } \\
\text { Constant } \gamma 1\end{array}$ & & $\begin{array}{c}\text { Material } \\
\text { Constant } \gamma 2\end{array}$ & $\begin{array}{c}\text { Constant C3 } \\
\text { [MPa] }\end{array}$ & $\begin{array}{c}\text { Material } \\
\text { Constant } \gamma 3\end{array}$ \\
\hline \multirow{2}{*}{ CuCrZr } & 20 & 180 & 300000 & 4000 & 30000 & 825 & 6000 & 45 \\
\hline & 350 & 152 & 200000 & 5000 & 30000 & 1000 & 6000 & 48 \\
\hline
\end{tabular}

Table 6: Bilinear parameters for elasto-plastic kinematic hardening model of $\mathrm{Cu}$ :

\begin{tabular}{cccc}
\hline & Temperature [C] & Yield Strength [MPa] & Tangent Modulus (MPa) \\
\hline & 20 & 57.39 & 1000 \\
Copper & 200 & 48.12 & 1000 \\
& 400 & 37.44 & 1000 \\
& 600 & 26.36 & 1000 \\
& 800 & 14.88 & 1000 \\
\hline
\end{tabular}




\section{Appendix B: Validation of simplified model}

This section compares the key results obtained with the simplified model to that of the central section of the full mock-up model. The comparison is carried out using a typical geometry. The full mock-up is modelled using 2 symmetries.

Figure 26: Meshed geometries of full mock-up and simplified model:
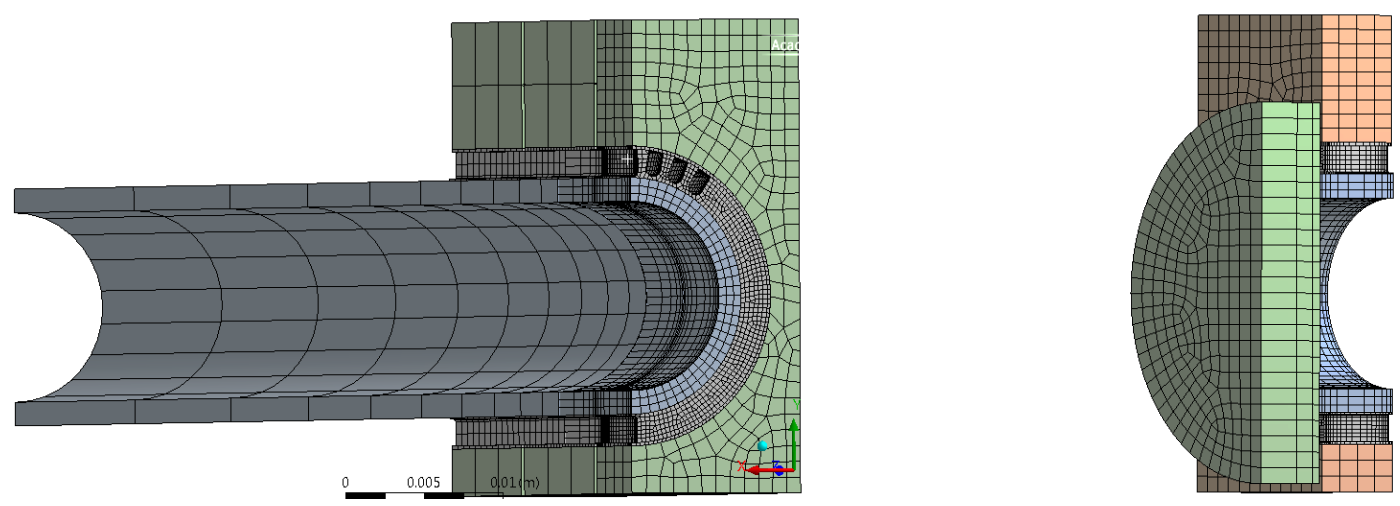

Table 7: Results comparison between full and simplified model (peak values):

\begin{tabular}{|c|c|c|c|c|c|c|}
\hline & $\begin{array}{l}\text { Temperature } \\
\text { Tungsten }\left[{ }^{\circ} \mathrm{C}\right]\end{array}$ & $\begin{array}{l}\text { Temperature } \\
\text { Copper }\left[{ }^{\circ} \mathrm{C}\right]\end{array}$ & $\begin{array}{c}\text { Temperature } \\
\text { Cooling Pipe }\left[{ }^{\circ} \mathrm{C}\right]\end{array}$ & $\begin{array}{l}\text { Secondary von- } \\
\text { Mises (pressure } \\
\text { only) [MPa] }\end{array}$ & $\begin{array}{c}\text { Fluctuating 3-Sm } \\
\text { Stress [MPa] }\end{array}$ & $\begin{array}{c}\text { Fluctuating } \\
\text { strain in Cu } \\
\text { interlayer [\%] }\end{array}$ \\
\hline Full model & 2571.4 & 787.6 & 428.6 & 40.4 & 260.0 & 6.77 \\
\hline Simplified model & 2569.6 & 786.0 & 428.6 & 41.3 & 266.2 & 6.26 \\
\hline Discrepancies & $-0.07 \%$ & $-0.2 \%$ & $0.0 \%$ & $2.2 \%$ & $2.3 \%$ & $-8.2 \%$ \\
\hline
\end{tabular}

\section{Appendix C: Further results details}

Table 8: Results summary for all criterion for the most promising designs, as pre-selected in section 6 . Result from phase 1 design is included at the bottom of the table:

\begin{tabular}{|c|c|c|c|c|c|c|c|c|c|c|c|}
\hline & Criterion reference $\rightarrow$ & [I] & {$[\mathrm{J}]$} & {$[\mathrm{H}]$} & {$[\mathrm{A}]$} & [F] & {$[\mathrm{K}]$} & [D] & [E] & [C] & [B] \\
\hline 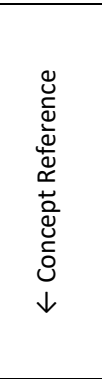 & Criterion Description $\rightarrow$ & 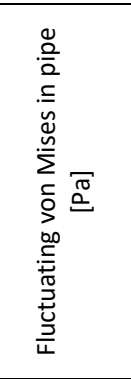 & 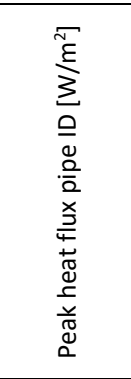 & 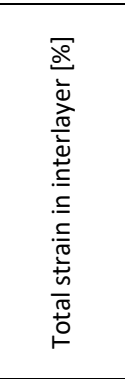 & 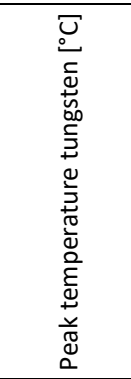 & 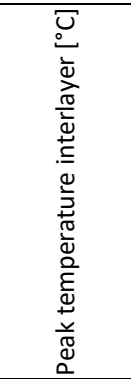 & 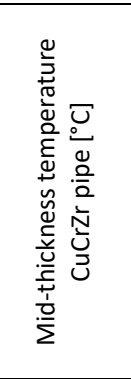 & 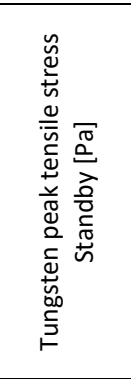 & 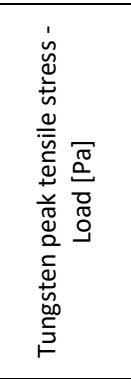 & 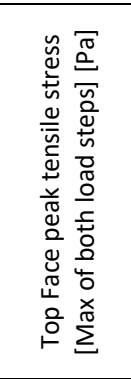 & 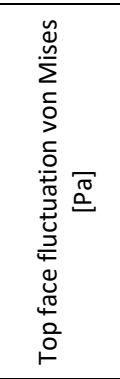 \\
\hline \multirow{2}{*}{ (a) } & $\begin{array}{c}4 \mathrm{~mm} \text { wide tungsten; } 2.0 \mathrm{~mm} \\
\text { interlayer \& } 1 \text { spoke }\end{array}$ & $2.27 \mathrm{E}+08$ & $3.01 \mathrm{E}+07$ & 8.83 & $2.53 E+03$ & $7.41 \mathrm{E}+02$ & $3.45 \mathrm{E}+02$ & $2.41 \mathrm{E}+08$ & $1.59 \mathrm{E}+08$ & $1.75 \mathrm{E}+07$ & $1.60 E+08$ \\
\hline & $\begin{array}{c}12 \mathrm{~mm} \text { wide tungsten; } 2.0 \mathrm{~mm} \\
\text { interlayer; } \& 1 \text { spoke }\end{array}$ & $2.23 E+08$ & $3.00 \mathrm{E}+07$ & 7.86 & $2.49 E+03$ & $7.37 \mathrm{E}+02$ & $3.45 \mathrm{E}+02$ & $2.41 \mathrm{E}+08$ & $1.58 \mathrm{E}+08$ & $1.71 \mathrm{E}+07$ & $1.51 E+08$ \\
\hline \multirow{2}{*}{ (b) } & $\begin{array}{l}4 \mathrm{~mm} \text { wide tungsten; } 1.5 \mathrm{~mm} \\
\text { interlayer \& } 1 \text { spoke }\end{array}$ & $2.46 \mathrm{E}+08$ & $3.10 E+07$ & 4.41 & $2.47 E+03$ & $6.27 \mathrm{E}+02$ & $3.51 E+02$ & $2.44 E+08$ & $1.23 \mathrm{E}+08$ & $2.06 \mathrm{E}+07$ & $1.58 \mathrm{E}+08$ \\
\hline & $\begin{array}{c}12 \mathrm{~mm} \text { wide tungsten; } 1.5 \mathrm{~mm} \\
\text { interlayer \& } 1 \text { spoke }\end{array}$ & $3.07 E+08$ & $3.22 \mathrm{E}+07$ & 5.36 & $2.47 \mathrm{E}+03$ & $6.32 \mathrm{E}+02$ & $3.55 \mathrm{E}+02$ & $3.16 \mathrm{E}+08$ & $2.46 \mathrm{E}+08$ & $1.97 \mathrm{E}+07$ & $2.27 \mathrm{E}+08$ \\
\hline \multirow{3}{*}{ (c) } & $\begin{array}{l}4 \mathrm{~mm} \text { wide tungsten; } 2.0 \mathrm{~mm} \\
\text { interlayer \& } 1 \text { spoke }\end{array}$ & $2.06 \mathrm{E}+08$ & $3.11 \mathrm{E}+07$ & 4.58 & $2.50 \mathrm{E}+03$ & $6.69 E+02$ & $3.52 E+02$ & $2.39 E+08$ & $1.51 \mathrm{E}+08$ & $2.04 \mathrm{E}+07$ & $1.60 E+08$ \\
\hline & $\begin{array}{l}12 \mathrm{~mm} \text { wide tungsten; } 2.0 \mathrm{~mm} \\
\text { interlayer } \& 1 \text { spoke }\end{array}$ & $2.03 E+08$ & $3.17 E+07$ & 5.63 & $2.46 \mathrm{E}+03$ & $6.68 \mathrm{E}+02$ & $3.53 E+02$ & $3.03 E+08$ & $2.57 \mathrm{E}+08$ & $1.95 \mathrm{E}+07$ & $2.18 \mathrm{E}+08$ \\
\hline & $\begin{array}{c}12 \mathrm{~mm} \text { wide tungsten; } 2.0 \mathrm{~mm} \\
\text { interlayer } \& 2 \text { spoke }\end{array}$ & $2.38 \mathrm{E}+08$ & $3.24 \mathrm{E}+07$ & 4.22 & $2.49 \mathrm{E}+03$ & $6.92 E+02$ & $3.56 \mathrm{E}+02$ & $2.85 \mathrm{E}+08$ & $2.57 E+08$ & $1.55 \mathrm{E}+07$ & $2.19 \mathrm{E}+08$ \\
\hline (d) & $\begin{array}{c}6.0 \mathrm{~mm} \text { lower \& } 7 \mathrm{~mm} \text { upper slot } \\
\text { position }\end{array}$ & $2.24 \mathrm{E}+08$ & $3.10 \mathrm{E}+07$ & 6.38 & $2.85 \mathrm{E}+03$ & $5.77 \mathrm{E}+02$ & $3.51 E+02$ & $2.61 \mathrm{E}+08$ & $1.88 \mathrm{E}+08$ & $8.63 \mathrm{E}+07$ & $2.51 E+08$ \\
\hline (e) & $\begin{array}{c}4 \text { holes } \& 4 \mathrm{~mm} \text { upper slot } \\
\text { position }\end{array}$ & $1.95 \mathrm{E}+08$ & $2.78 \mathrm{E}+07$ & 5.28 & $2.93 E+03$ & $6.37 E+02$ & $3.39 \mathrm{E}+02$ & $2.08 \mathrm{E}+08$ & $1.23 \mathrm{E}+08$ & $7.24 \mathrm{E}+06$ & $1.01 \mathrm{E}+08$ \\
\hline (f) & $30^{\circ} \& 1$ spokes & $2.00 \mathrm{E}+08$ & $3.13 \mathrm{E}+07$ & 6.44 & $2.45 E+03$ & $6.46 \mathrm{E}+02$ & $3.48 \mathrm{E}+02$ & $3.25 \mathrm{E}+08$ & $2.51 \mathrm{E}+08$ & $2.45 \mathrm{E}+07$ & $2.20 E+08$ \\
\hline $\begin{array}{l}\text { Phase } 1 \\
\text { Design }\end{array}$ & $\begin{array}{c}\text { MPAP_V5.37.SI; FullMockup; } \\
20 \mathrm{MW} / \mathrm{m}^{2}\end{array}$ & $2.85 E+08$ & $3.19 E+07$ & $5.86 \mathrm{E}+00$ & $1.95 \mathrm{E}+03$ & $7.45 E+02$ & $3.46 \mathrm{E}+02$ & $1.48 \mathrm{E}+08$ & $3.45 \mathrm{E}+08$ & $2.34 \mathrm{E}+07$ & \\
\hline
\end{tabular}


Figure 27: Response surfaces file for the final design, each surface plot corresponds to a design criterion. Results that are out of specification are highlighted in orange:
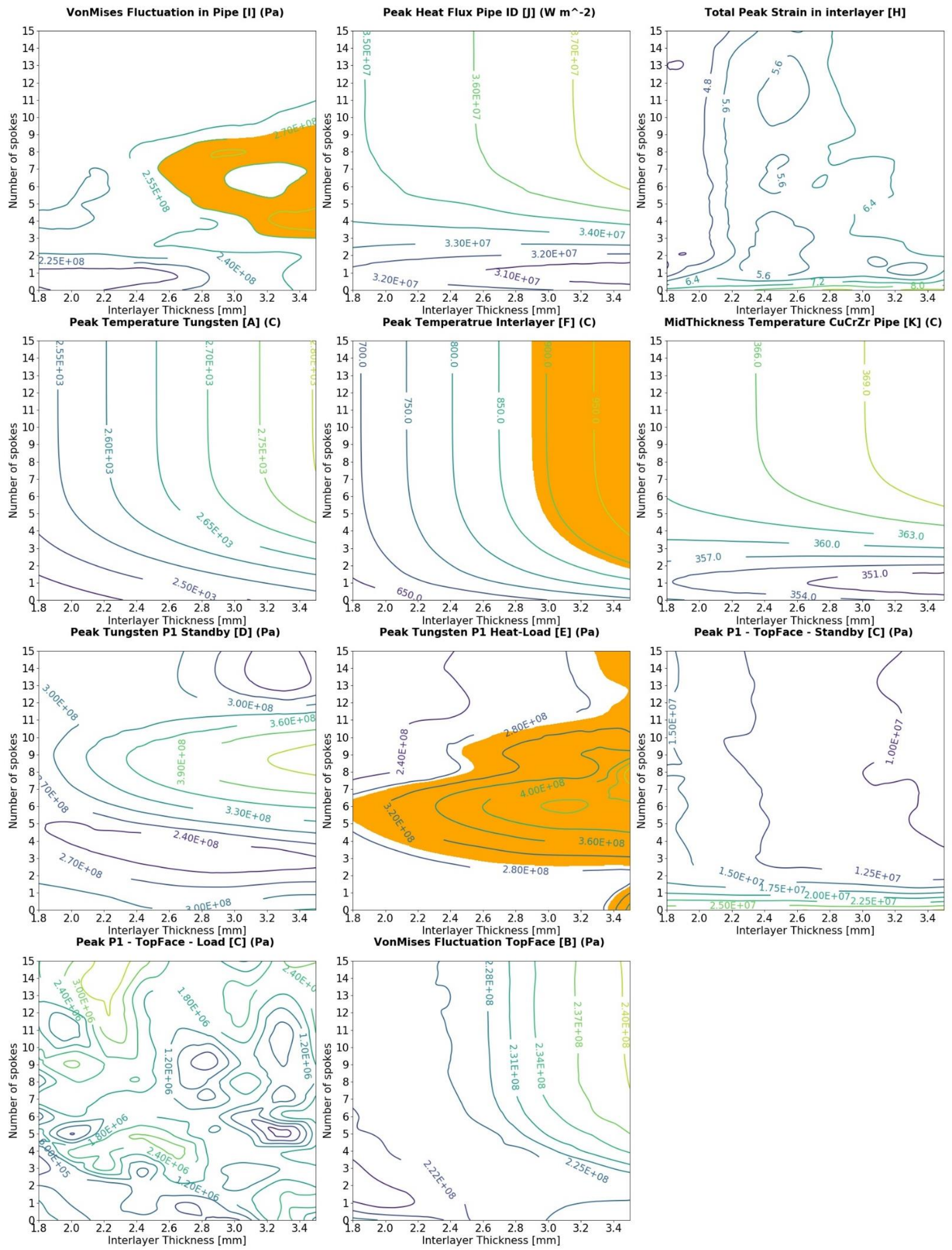
Table 9: Summary of performance for the definitive design as a standalone model compared with response surface results:

\begin{tabular}{|c|c|c|c|c|}
\hline Parameters & Criterion ID & Results from Standalone model & Results from Response surfaces & Discrepancies \\
\hline \multicolumn{5}{|l|}{ Tungsten armour: } \\
\hline Temperature Tungsten $\left[{ }^{\circ} \mathrm{C}\right]$ & A & 2485 & 2485 & $0.0 \%$ \\
\hline V.M. fluctuation, top face [MPa] & B & 219 & 219 & $0.0 \%$ \\
\hline Abs. tensile stress, top face [MPa] & c & 15.8 & 15.5 & $1.9 \%$ \\
\hline Tungsten P1 Standby [MPa] & D & 285 & 285 & $0.0 \%$ \\
\hline Tungsten P1 Load [MPa] & $\mathrm{E}$ & 257 & 257 & $0.0 \%$ \\
\hline \multicolumn{5}{|l|}{ Cupper interlayer: } \\
\hline Temperature Interlayer $\left[{ }^{\circ} \mathrm{C}\right]$ & $\mathrm{F}$ & 692 & 692 & $0.0 \%$ \\
\hline Total Strain fluctuation [\%] & $\mathrm{H}$ & 4.70 & 4.22 & $11.4 \%$ \\
\hline \multicolumn{5}{|l|}{ CuCrZr Cooling pipe: } \\
\hline V.M. fluctuation [MPa] & 1 & 239 & 238 & $0.4 \%$ \\
\hline Total Heat Flux Pipe ID $\left[\mathrm{MWm}^{-2}\right]$ & $\mathrm{J}$ & 32.4 & 32.4 & $0.0 \%$ \\
\hline Temperature pipe $\left[{ }^{\circ} \mathrm{C}\right]$ & $\mathrm{K}$ & 357 & 356 & $0.3 \%$ \\
\hline
\end{tabular}

Figure 28: Results plots from the F.E. model of the definitive design, order of plots are similar to that shows in Table 9:
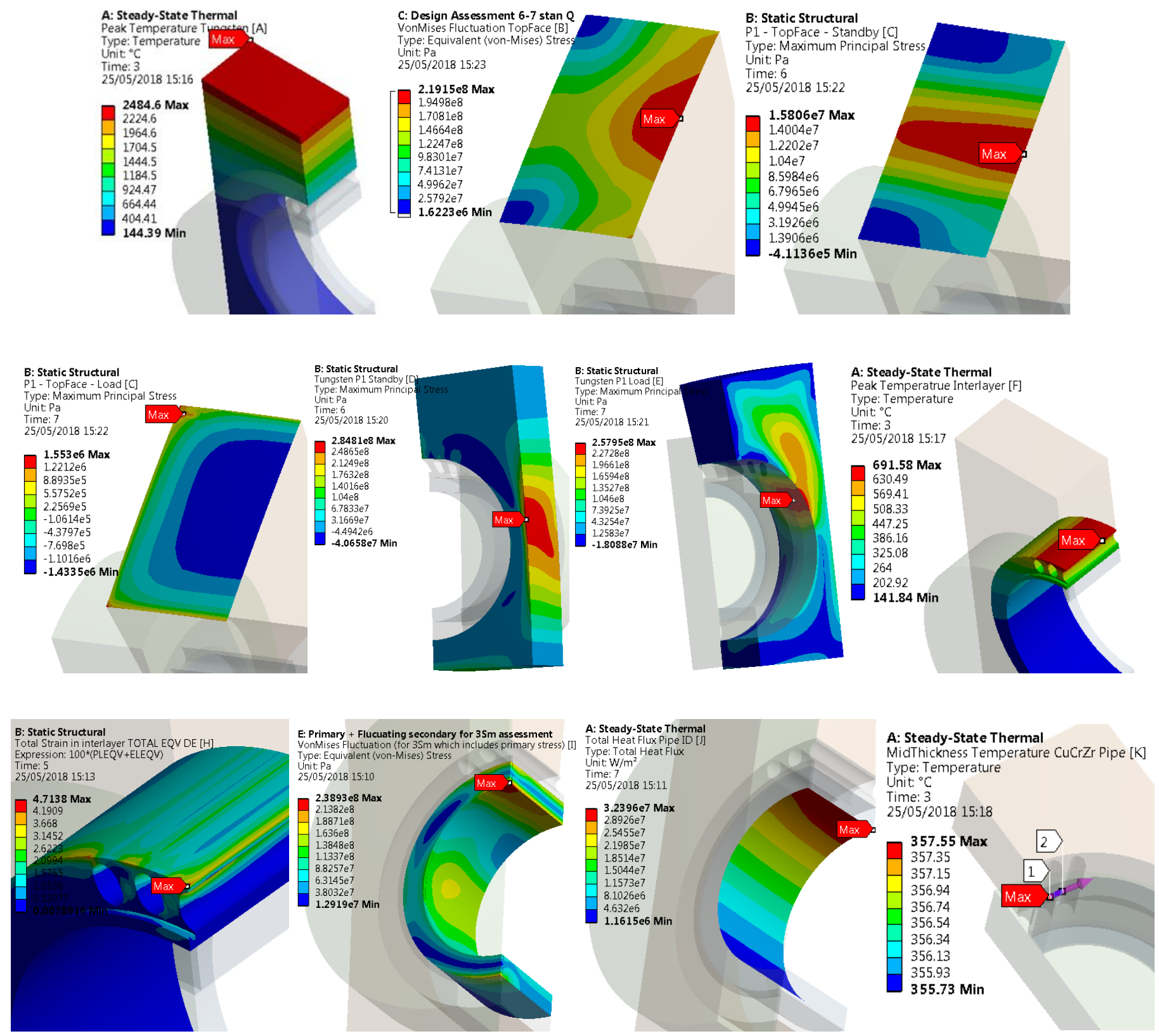